\title{
Congenital and hereditary cystic diseases of the abdomen
}

\author{
Ali Devrim Karaosmanoglu*, Sevtap Arslan, Deniz Akata, Mustafa Ozmen, Mithat Haliloglu, Berna Oguz \\ and Musturay Karcaaltincaba
}

\begin{abstract}
Congenital and hereditary cystic lesions of the abdomen are relatively rare. Correct diagnosis is critical as they may simulate several other benign and malignant acquired diseases of the abdomen. With the correct and appropriate use of imaging, diagnosis may be relatively straightforward and clinical management may be implemented appropriately. The purpose of this article is to describe imaging findings of common and uncommon congenital and hereditary cystic disease of the abdominal organs.
\end{abstract}

Keywords: Abdomen, Cystic lesions, Hereditary, Congenital

\section{Key Points}

- The detection of incidental cystic lesions may cause diagnostic confusion in patients having a history of cancer.

- Some syndromes predisposing the affected individual to different tumors may cause cystic lesions in the abdominal organs and rarely, the tumors can be cystic.

- Correct diagnosis of the benign cystic lesions is critical as they may simulate several other benign and malignant acquired diseases of the abdomen, all of which have very different treatment approaches and prognostic implications.

\section{Introduction}

Abdominal cystic lesions may originate from parenchymatous organs or from nonparenchymatous structures and may be congenital, hereditary, or acquired. The organ of origin, the position of the cystic lesion, and specific imaging findings are useful in the differential diagnosis. Ultrasonography (US), computed tomography $(\mathrm{CT})$, and magnetic resonance imaging (MRI) may be

* Correspondence: alidevrim76@yahoo.com

Department of Radiology, Hacettepe University School of Medicine, 06100 Ankara, Turkey

\section{Springer Open}

used for imaging, all of which have pros and cons. The US, which is widely available and less expensive, can be preferable in pediatric patients because of the lack of ionizing radiation and the opportunity of real-time imaging but one of its main disadvantages is operator dependence. CT and MRI may also be used for assessment of the anatomical relations and, in addition, the internal content of these cystic structures may also be effectively evaluated with these modalities. They can be used for follow-up purposes for lesions with a potential risk of malignant transformation. One of the main advantages of CT as compared to MRI is its allowance of rapid image acquisition, especially in non-cooperative patients. MRI, which provides high soft-tissue resolution, might be preferable for follow-up, especially in young patients, due to lack of ionizing radiation. Knowledge of the typical imaging findings for cystic diseases can help radiologists in establishing the correct diagnosis. So, the radiologist can provide valuable information to the clinician to guide further management. In this review, we describe imaging findings of the congenital and hereditary cystic diseases of the abdomen. A detailed literature search was also carried out to be able to summarize the radiological findings of these particular cystic diseases (Table 1) [1-33].

(c) The Author(s). 2020 Open Access This article is licensed under a Creative Commons Attribution 4.0 International License, which permits use, sharing, adaptation, distribution and reproduction in any medium or format, as long as you give appropriate credit to the original author(s) and the source, provide a link to the Creative Commons licence, and indicate if changes were made. The images or other third party material in this article are included in the article's Creative Commons licence, unless indicated otherwise in a credit line to the material. If material is not included in the article's Creative Commons licence and your intended use is not permitted by statutory regulation or exceeds the permitted use, you will need to obtain permission directly from the copyright holder. To view a copy of this licence, visit http://creativecommons.org/licenses/by/4.0/. 
Table 1 Congenital and hereditary cystic diseases of the abdomen. Associated radiological findings.

\begin{tabular}{|c|c|c|c|}
\hline \multirow{4}{*}{$\frac{\text { Organ }}{\text { Liver and biliary tract }}$} & \multicolumn{2}{|l|}{ Disease } & \multirow[b]{2}{*}{$\begin{array}{l}\text { Typical imaging findings } \\
\text { - Cysts located within the peripheral parenchyma } \\
\text { - Peribiliary cysts } \\
\text { - Fluid level, cyst wall thickening, calcification and endocavitary air bubbles, } \\
\text { if infection is present } \\
\text { - Hyperdensity on CT and hyperintensity on T1W MR images could be seen } \\
\text { due to the hemorrhage or infection }\end{array}$} \\
\hline & \multicolumn{2}{|c|}{ Polycystic liver disease } & \\
\hline & \multicolumn{2}{|l|}{ Caroli disease } & $\begin{array}{l}\text { - Cystic appearing enlarged intrahepatic bile ducts } \\
\text { - Central dot sign (portal radicle within the dilated bile duct) } \\
\text { - Endoluminal stones or sludge may be observed }\end{array}$ \\
\hline & \multirow[t]{5}{*}{ Choledochal cysts } & Type-l & $\begin{array}{l}\text { - Type IA: Diffuse cystic dilation of the extrahepatic bile duct } \\
\text { - Type IB: Focal cystic dilation of the extrahepatic bile duct } \\
\text { - Type IC: Diffuse fusiform dilation of the entire extrahepatic bile duct }\end{array}$ \\
\hline & & Type-II & - Focal diverticular outpouching of the common bile duct \\
\hline & & Type--III & $\begin{array}{l}\text { - Intramural dilation of the most distal portion of the common bile duct } \\
\text { (choledochocele) }\end{array}$ \\
\hline & & Type-IV & $\begin{array}{l}\text { - Type IVA: Combined saccular shaped dilations in the intrahepatic and } \\
\text { extrahepatic bile ducts } \\
\text { - Type IVB: Saccular dilations restricted to extrahepatic bile ducts }\end{array}$ \\
\hline & & Type-V & - Caroli disease \\
\hline & \multicolumn{2}{|c|}{$\begin{array}{l}\text { Biliary hamartomas(von Meyenburg } \\
\text { complex) }\end{array}$} & - Innumerable subcentimeter cysts spread throughout the liver parenchyma \\
\hline & \multicolumn{2}{|c|}{ Ciliated hepatic foregut cyst } & $\begin{array}{l}\text { - Unilocular cystic lesion located in the subcapsular area along the anterior } \\
\text { surface of the liver with segment } 4 \text { being the most common location }\end{array}$ \\
\hline \multirow[t]{6}{*}{$\begin{array}{l}\text { Kidney } \\
*[10-19]\end{array}$} & \multicolumn{2}{|c|}{$\begin{array}{l}\text { Autosomal dominant polycystic kidney } \\
\text { disease }\end{array}$} & $\begin{array}{l}\text { - Early stage: Single or multiple cysts in one or both kidneys } \\
\text { - Final stage: Multiple cysts completely replacing the entire renal parenchyma } \\
\text { - Hyperdensity on } C T^{(a)} \text { and hyperintensity on } \operatorname{TIW}^{(\mathrm{b})} \mathrm{MR}^{(\mathrm{c})} \text { images in case } \\
\text { of hemorrhage }\end{array}$ \\
\hline & \multicolumn{2}{|c|}{$\begin{array}{l}\text { Autosomal recessive polycystic kidney } \\
\text { disease }\end{array}$} & $\begin{array}{l}\text { - Enlarged kidneys with thickened hyperechoic parenchyma caused by } \\
\text { microcysts } \\
\text { - Larger cysts (>1 cm) may accompany in some cases } \\
\text { - Suggestive findings of hepatic abnormalities including congenital hepatic } \\
\text { fibrosis, Caroli disease, and bile duct ectasia }\end{array}$ \\
\hline & \multicolumn{2}{|c|}{ Multicystic dysplastic kidney disease } & $\begin{array}{l}\text { - Unilateral cysts in disorganized pattern completely replacing the renal } \\
\text { parenchyma, which may be observed on antenatal US }\end{array}$ \\
\hline & \multicolumn{2}{|c|}{$\begin{array}{l}\text { Nephronophthisis and medullary cystic } \\
\text { kidney disease }\end{array}$} & $\begin{array}{l}\text { - Early stage: Hyperechoic renal parenchyma with the loss of corticomedullary } \\
\text { differentiation } \\
\text { - Advanced stage: Cysts, of varying size, in medullary and corticomedullary } \\
\text { locations. The kidneys appear small due to parenchymal fibrosis }\end{array}$ \\
\hline & \multicolumn{2}{|c|}{ Von Hippel-Lindau disease } & $\begin{array}{l}\text { - Bilateral renal cysts of varying histopathologic features, ranging from simple } \\
\text { and hyperplastic cysts to cystic clear cell carcinomas }\end{array}$ \\
\hline & \multicolumn{2}{|c|}{ Tuberous sclerosis complex } & - Bilateral simple renal cysts with accompanying angiomyolipomas \\
\hline \multirow[t]{3}{*}{$\begin{array}{l}\text { Pancreas } \\
{ }^{*}[20-23]\end{array}$} & \multicolumn{2}{|c|}{ Von Hippel-Lindau disease } & $\begin{array}{l}\text { - Simple cysts } \\
\text { - Serous cystadenomas } \\
\text { - Cystic or solid neuroendocrine tumors }\end{array}$ \\
\hline & \multicolumn{2}{|c|}{ Multiple endocrine neoplasia type I } & - Cystic or solid neuroendocrine tumors \\
\hline & \multicolumn{2}{|l|}{ Cystic fibrosis } & $\begin{array}{l}\text { - Complete or partial fatty replacement of the pancreas } \\
\text { - Atrophy of the pancreas } \\
\text { - Simple cysts completely replacing the parenchyma (pancreatic cystosis) }\end{array}$ \\
\hline $\begin{array}{l}\text { Gastrointestinal tract } \\
*[24-26]\end{array}$ & \multicolumn{2}{|l|}{ Duplication cysts } & $\begin{array}{l}\text { - Cyst within the close proximity of the bowel segment } \\
\text { - The double wall sign (inner hyperechoic mucosa and outer hypoechoic } \\
\text { muscularis propria) } \\
\text { - "Y configuration" that is indicative of a shared wall with the cyst and the } \\
\text { neighboring bowel wall } \\
\text { - Internal septation or luminal debris may be observed due to the infection }\end{array}$ \\
\hline $\begin{array}{l}\text { Lymphatic system } \\
*[27,28]\end{array}$ & \multicolumn{2}{|c|}{ Lymphatic malformations } & $\begin{array}{l}\text { - Well-circumscribed cystic lesion with internal septations } \\
\text { - The fluid content of the lesion may contain fat } \\
\text { - Small lesions may change location on follow-up imaging }\end{array}$ \\
\hline
\end{tabular}


Table 1 Congenital and hereditary cystic diseases of the abdomen. Associated radiological findings. (Continued)

\begin{tabular}{|c|c|c|}
\hline Organ & Disease & Typical imaging findings \\
\hline $\begin{array}{l}\text { Diaphragm } \\
*[29]\end{array}$ & Mesothelial cyst & $\begin{array}{l}\text { - Homogeneous bilobulated cystic lesion located between posterolateral } \\
\text { aspect of the right liver lobe and the adjacent diaphragm }\end{array}$ \\
\hline \multirow[t]{2}{*}{$\begin{array}{l}\text { Prostate } \\
*[30,31]\end{array}$} & Prostatic utricle cyst & $\begin{array}{l}\text { - Midline cyst communicating with the prostatic urethra and not extending } \\
\text { above the base of the prostate }\end{array}$ \\
\hline & Mullerian duct cyst & $\begin{array}{l}\text { - Teardrop-shaped midline cyst extending above the superior margin of the } \\
\text { prostate and not communicating with the prostatic urethra }\end{array}$ \\
\hline $\begin{array}{l}\text { Urachus } \\
*[32]\end{array}$ & Urachal cyst & $\begin{array}{l}\text { - Homogeneous midline cyst along the trajectory of the urachus (between } \\
\text { the bladder dome and umbilicus) } \\
\text { - Inhomogeneous cyst content, cyst wall thickening, and inflammatory } \\
\text { stranding adjacent to the cyst indicate infection }\end{array}$ \\
\hline $\begin{array}{l}\text { Zinner's syndrome } \\
*[33]\end{array}$ & Seminal vesicle cysts & $\begin{array}{l}\text { - Ipsilateral renal agenesis, seminal vesicle cysts, and ejaculatory duct obstruction } \\
\text { - In case of hemorrhage or infection the cyst content may appear as bright on } \\
\text { T1W MR images }\end{array}$ \\
\hline
\end{tabular}

*: References, ${ }^{\left({ }^{(a)}\right.}$ CT: Computed tomography, ${ }^{(b)}$ T1W: T1-weighted, ${ }^{(c)}$ MR: Magnetic resonance, ${ }^{(d)}$ US: Ultrasonography

\section{Liver and biliary tract Polycystic liver disease}

Polycystic liver disease (PLD) is a part of the spectrum of fibropolycystic liver disease. It has an autosomal dominant inheritance pattern and may also be related to polycystic kidney disease (PKD). This association with PKD is not rare and may be seen in around $50 \%$ of the patients [34]. It is a rare disease, with an estimated incidence of $<0.01 \%$, with a slight female preponderance [34, 35]. Genetic mechanisms are the most important underlying cause which gives rise to the separation of ductal structures from the biliary tree, ultimately resulting in cyst formation [36]. These disconnected bile ducts typically remain clinically silent until cysts begin to form in adulthood [36]. These cysts are not distinct from simple hepatic cysts from a histopathologic standpoint. Their walls are lined by cuboidal biliary epithelium and contain serous fluid in their cavities [1]. The cysts tend to emerge after puberty and they generally remain asymptomatic. Cyst rupture, hemorrhage, or infection may be counted among the potential complications of these cysts. Malignant degeneration and liver failure are rare. Liver transplantation is reserved for symptomatic relief [37].

On cross-sectional imaging, the cysts are typically located within the peripheral parenchyma (Fig. 1). They highly vary in size, ranging from a few millimeters to 80 $\mathrm{mm}[1]$. The peribiliary cysts, in the periportal distribution, may also be seen and they are typically small $(<10$ $\mathrm{mm}$ ) (Fig. 2). The cysts tend to increase both in size and number with the advancing age. Infected or hemorrhagic cysts may appear as hyperdense on CT and hyperintense on T1-weighted (T1W) MR images [2] (Fig. 3). Fluid level, cyst wall thickening, calcification, or endocavitary air bubbles may be seen in infected cysts [3]. Noncomplicated cysts have well-defined margins and the cyst walls are smooth without any mural nodularity.
Considering the LI-RADS v2018 (Liver Imaging Reporting and Data System Version 2018), non-complicated cysts are categorized as LR-1 lesions, which also include typical hemangiomas, vascular anomaly, confluent fibrosis, hepatic fat deposition or sparing, and focal scar [38]. Hepatocyte-specific contrast agents are useful for demonstrating the absence of any communication between the biliary system and the cysts [2]. Although it is rare, the possibility of concomitant cholangiocarcinoma should be considered in patients with PLD and abnormal liver function tests [39] (Fig. 4).

\section{Caroli disease}

Caroli disease (CD) manifests with saccular, nonobstructive, multisegmental dilation of the large intrahepatic bile ducts [4]. The disease is mostly inherited in an autosomal recessive fashion. In the so-called pure form

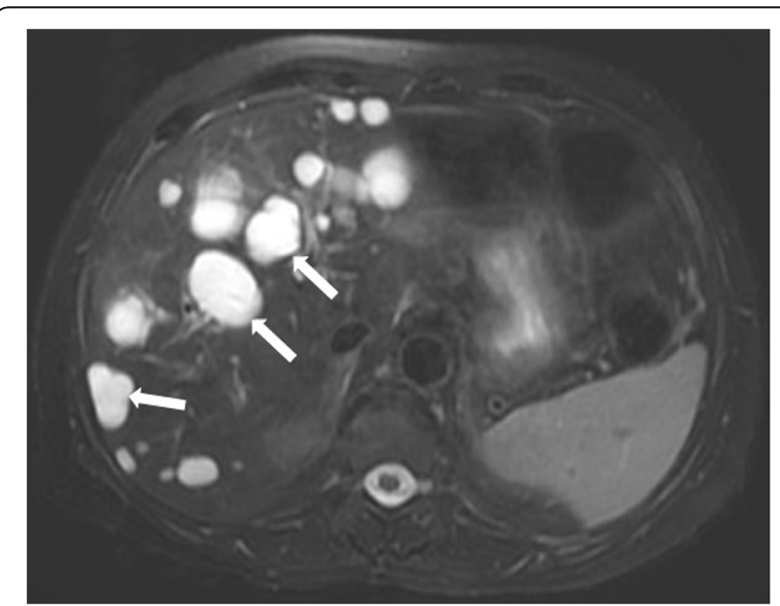

Fig. 1 A 60-year-old female patient with known long-standing PLD. Axial plane T2W fat-saturated MR image shows multiple parenchymal cysts in the liver (arrows) 


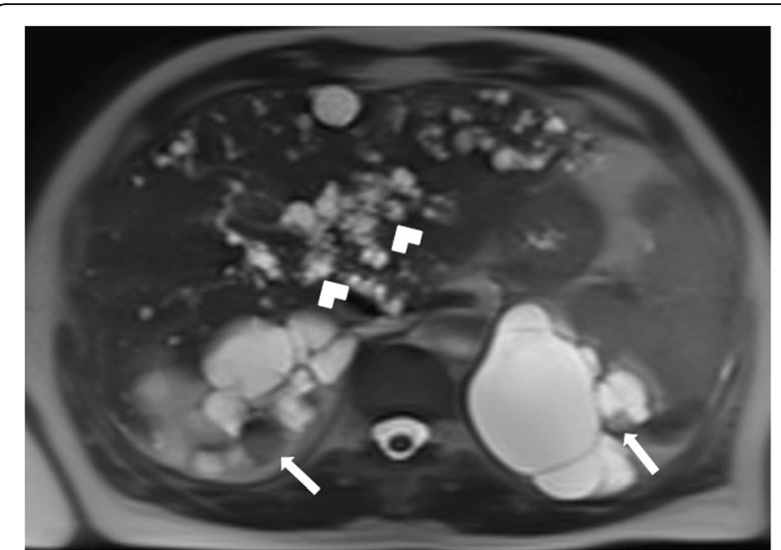

Fig. 2 A 55-year-old female patient with known ADPKD and PLD. Axial plane T2W fat-saturated MR image shows multiple bilateral renal cysts with hemorrhagic cysts (arrows) and peribiliary cysts (arrowheads) in the liver

of $\mathrm{CD}$, there is no associating background parenchymal liver abnormality. In the coexistence of $\mathrm{CD}$ and congenital hepatic fibrosis, the disease process is called as the "Caroli syndrome", which is the more commonly encountered disease form. $\mathrm{CD}$ is also included in the Todani classification and classified as type $\mathrm{V}$ abnormality [4]. The disease mostly manifests around 30 years of age; however, patients with Caroli syndrome may present earlier.

On imaging, cystic appearing enlarged intrahepatic bile ducts (in a saccular fashion) up to $5 \mathrm{~cm}$ in diameter is

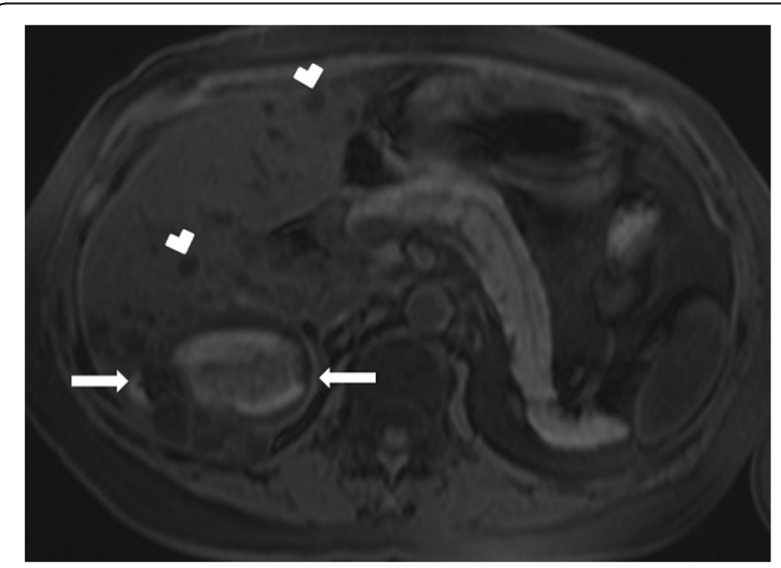

Fig. 3 A 44-year-old female patient with known PLD presenting with right upper quadrant pain. On the US, a large hyperechoic mass was found in the right hepatic lobe (not shown). Axial plane precontrast T1W MR image shows subcentimeter cysts (arrowheads) and a cystic lesion with hyperintense content (arrows). There was no discernible enhancement on postcontrast series (not shown). Imaging findings were found to be consistent with the hemorrhagic cyst. Follow-up imaging studies demonstrated the decrease in the size of the lesion

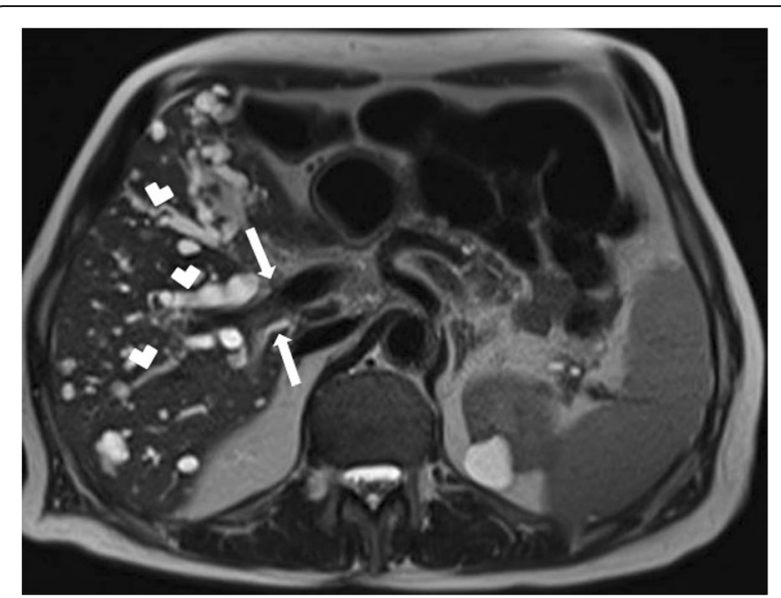

Fig. 4 A 60-year-old male patient with known PLD presenting with recent onset jaundice. Axial plane T2W MR image demonstrates innumerable cysts scattered throughout the liver parenchyma. Also, note is made of dilation in the intrahepatic bile ducts (arrowheads). This dilation abruptly ends at the confluence of the right and left hepatic ducts (arrow). The patient underwent endoscopic retrograde cholangiopancreatography and endoscopic brush biopsy confirmed Klatskin tumor.

the classic finding. Endoluminal stones or sludge may be observed in these enlarged bile ducts. The detection of "central dot sign" is highly suggestive for $\mathrm{CD}$ (Fig. 5). This imaging finding refers to portal radicle within these dilated bile ducts and they tend to show strong enhancement after contrast injection [4]. Magnetic resonance cholangiopancreatography (MRCP) is helpful not only for detecting the presence of endoluminal abnormalities but also for demonstrating the extent of the disease (Fig. 6). The extrahepatic bile ducts are typically not affected and disease may be

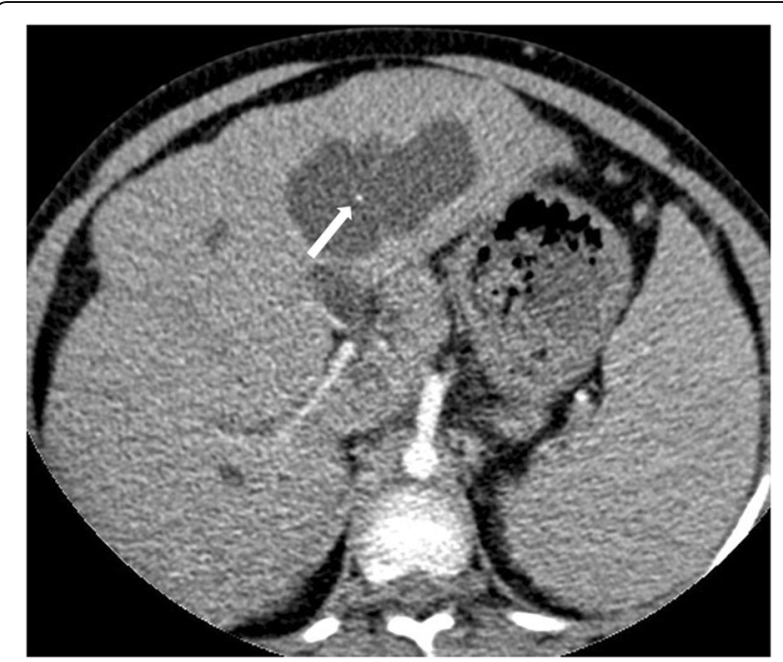

Fig. 5 A 6-year-old male patient with known Caroli syndrome. Axial plane arterial phase CT image shows central dot sign (arrow) 

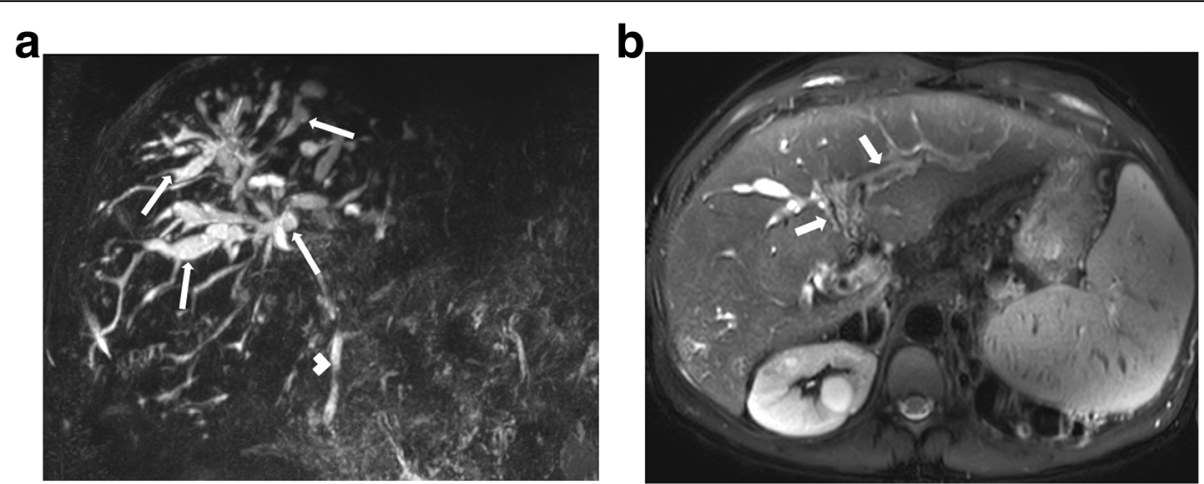

Fig 6 A 30-year-old male patient with known Caroli syndrome presenting with jaundice. a Coronal plane MRCP MIP (maximum intensity projection) image shows multifocal segmental dilation of the intrahepatic bile ducts (arrows). Choledoc is normal (arrowhead). b Axial plane T2W fat-saturated MR image shows increased T2 signal in the periportal area (arrows) and surface irregularity of the liver. These findings are consistent with congenital hepatic fibrosis

bilobar or limited to one lobe, mostly the left lobe. Surgical resection of the affected liver lobe or segment may be curative in limited disease. Hepatocytespecific contrast agents may be helpful for demonstrating the communication between the parenchymal cysts and the biliary system.

\section{Choledochal cysts}

Choledochal cysts are rare congenital malformations of the extrahepatic and intrahepatic biliary system. They are more common in females and the incidence is higher in Asian countries [5]. The most commonly accepted classification is proposed by Todani et al. in 1977 [6].

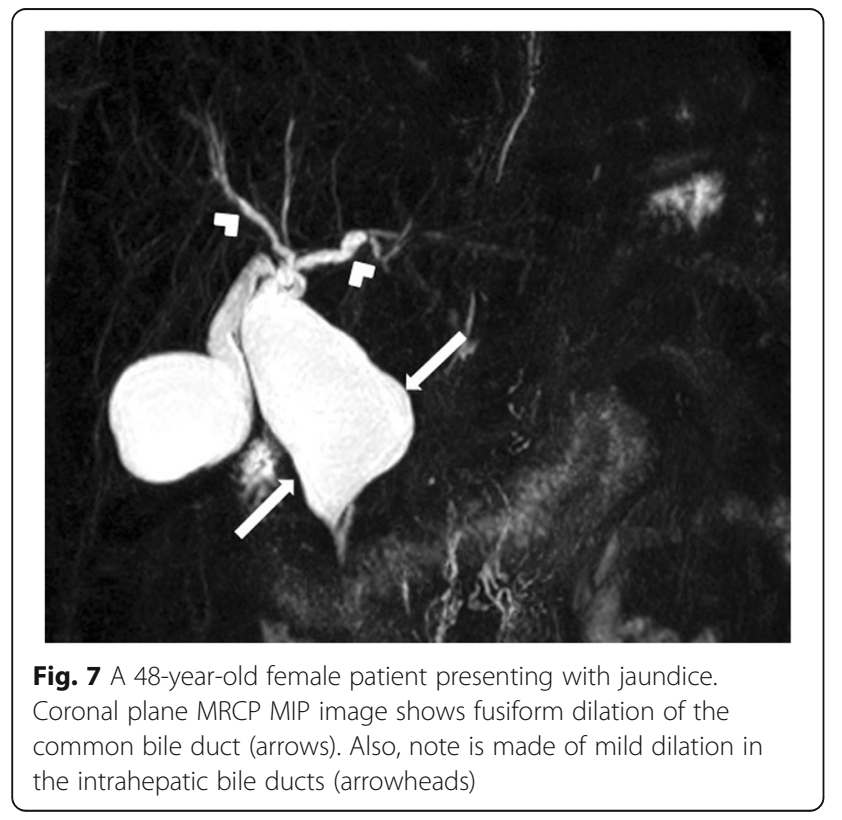

Type I: This group has been subclassified into three subgroups with type IC being the most common. Type IA refers to diffuse cystic dilation of the extrahepatic bile duct whereas type IB is seen as focal cystic dilation in the extrahepatic bile duct. Type IC is characterized by diffuse fusiform dilation of the entire extrahepatic bile duct (Fig. 7).

Type II: This type is the least common one with focal diverticular outpouching of the common bile duct (Fig. 8).

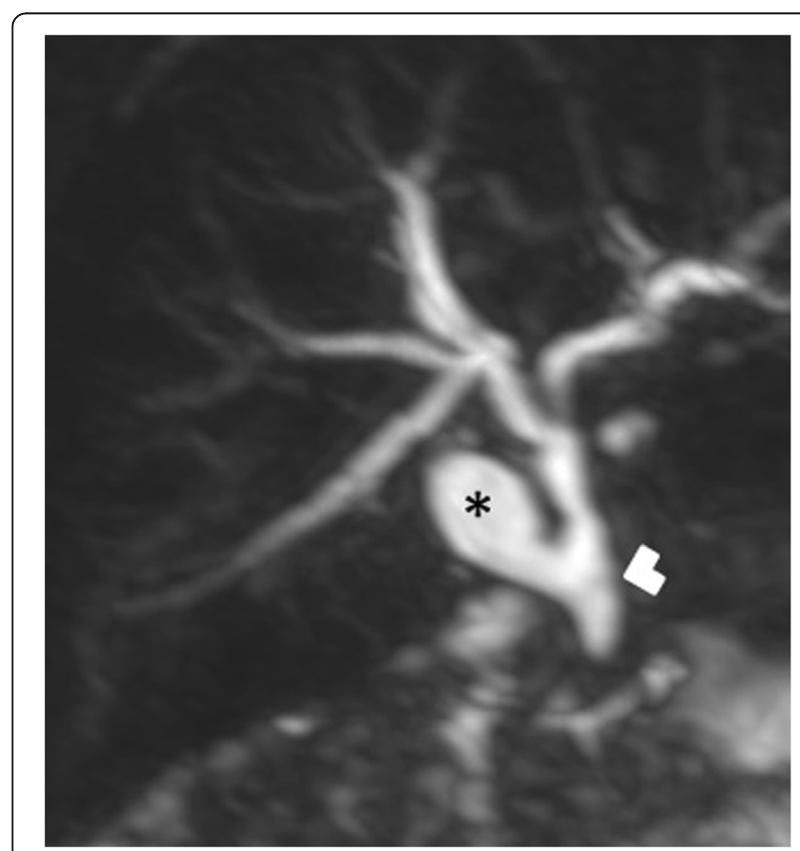

Fig. 8 A 2-year-old female patient presenting with jaundice. On the US, a saccular outpouching arising from the supraduodenal extrahepatic bile duct was found (not shown). Coronal plane MRCP MIP image shows a diverticulum (asterisk), arising from the supraduodenal extrahepatic bile duct (arrowhead) 

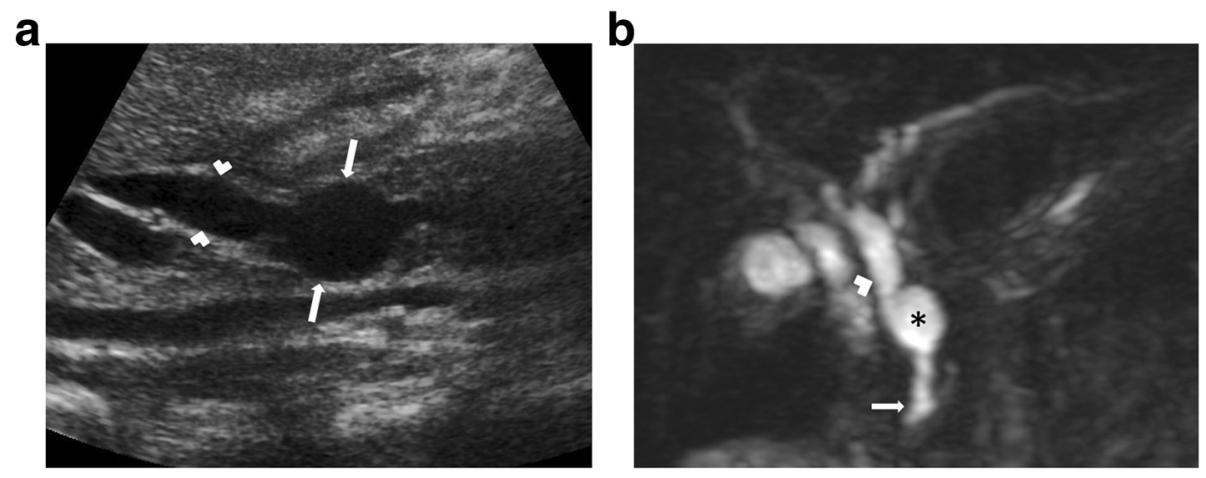

Fig 9 An 11-year-old female patient with newly diagnosed Hodgkin lymphoma underwent an initial US exam. a US image reveals choledochocele (long arrows) that involves the intramural segment of the distal common bile duct (arrowheads). b Coronal plane MRCP MIP image shows choledochocele (asterisk), common bile duct (arrowhead), and duodenum (arrow)

Type III: This group is also known as choledochoceles and refers to intramural dilation of the most distal portion of the common bile duct (Fig. 9).

Type IV: This group has been subclassified into two subgroups. Type IVA is characterized by combined saccular-shaped dilations in the intrahepatic and extrahepatic bile ducts. Type IVB refers to saccular dilations restricted to extrahepatic bile ducts (Fig. 10).

Type V: This group is also known as Caroli disease.

Choledochal cysts typically manifest before the age of 10 years. The diagnosis is typically made after the clinical emergence of complications. Among these potential complications, cholangitis and pancreatitis are the most common. Malignancy may also be seen in the course of

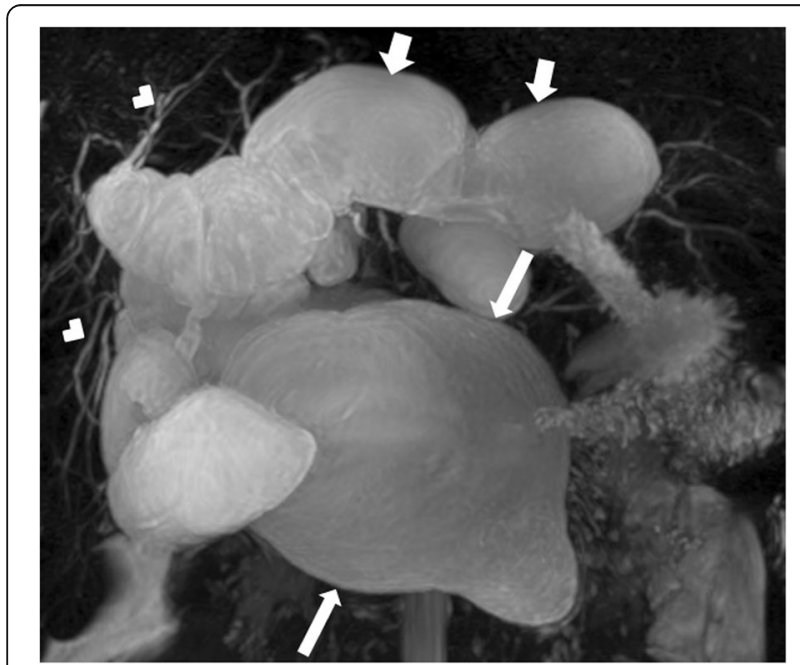

Fig. 10 A 23-year-old pregnant patient presenting with jaundice. Coronal plane MRCP MIP image shows fusiform dilation of the entire extrahepatic bile duct (long arrows) with extensive dilation of the intrahepatic bile ducts in the left lobe (short arrows). Intrahepatic bile ducts in the right lobe are normal (arrowheads) the disease. The risk of malignancy development is not rare (around $10-15 \%$ of the cases) with the extrahepatic biliary system and gallbladder being the most common $[40,41]$.

\section{Biliary hamartomas}

Biliary hamartomas, also known as the "von Meyenburg complex (VMC)" was first described in 1918 and is characterized by the presence of multiple bile duct hamartomas [7]. Histopathologically, they are composed of abnormally dilated intrahepatic bile ducts embedded in a fibrous stroma. The prevalence of this abnormality is between $0.6 \%$ and $2.8 \%$ on autopsy studies [8]. This abnormality is asymptomatic in the majority of the patients and is incidentally detected [7]. The detection of biliary hamartomas may cause diagnostic confusion in patients having a history of cancer.

These lesions appear as focal hypodense lesions on CT sometimes with irregular borders (Fig. 11). They typically do not enhance after contrast injection. T2-weighted (T2W) MR images are very helpful for diagnosis as biliary hamartomas are typically homogeneously hyperintense (Fig. 11) whereas they are seen as hypointense on T1W images with no apparent contrast enhancement on dynamic T1W 3D gradient echo sequences. The cysts are generally subcentimeter in diameter and innumerable spread throughout the liver parenchyma [7].

\section{Ciliated hepatic foregut cyst}

Ciliated hepatic foregut cysts (CHFC) are generally asymptomatic and they are most commonly diagnosed incidentally on imaging or during surgery [42]. It has been proposed that CHFCs originate from intrahepatically entrapped detached hepatic diverticulum or abnormal tracheobronchiolar bud that may have migrated caudally at the early stages of the embryonic 

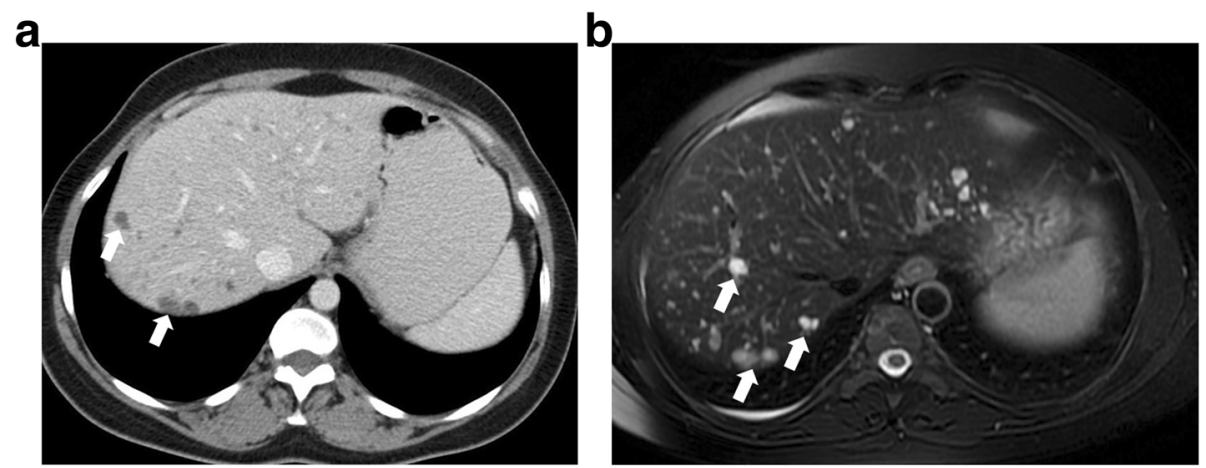

Fig. 11 A 48-year-old female patient with known breast cancer underwent abdominal CT scanning for distant metastasis evaluation. a Axial plane post-contrast CT image shows multiple hypodense lesions (arrows) in both liver lobes. b Axial plane fat-saturated T2W MR image shows multiple cystic lesions (arrows) consistent with biliary hamartomas

development of the foregut [43]. It is a very rare clinical finding and histopathologically, they are composed of ciliated, pseudostratified columnar epithelium, a layer of subepithelial connective tissue, a smooth muscle layer, and outer capsule [44]. Management strategy is controversial but a more aggressive approach such as surgical resection has been recommended as the malignant transformation has been reported in few cases [9]. They are more common in men and the medial segment of the left hepatic lobe (segments $4 \mathrm{~A}$ and $4 \mathrm{~B}$ ) is the most common location.

On US and cross-sectional imaging, they typically appear as unilocular cystic lesion located in the subcapsular area along the anterior surface of the liver (Fig. 12). The mean size is $3 \mathrm{~cm}$, with a range of $1-12 \mathrm{~cm}$ [9]. They are seen as hypodense lesions on CT studies with a

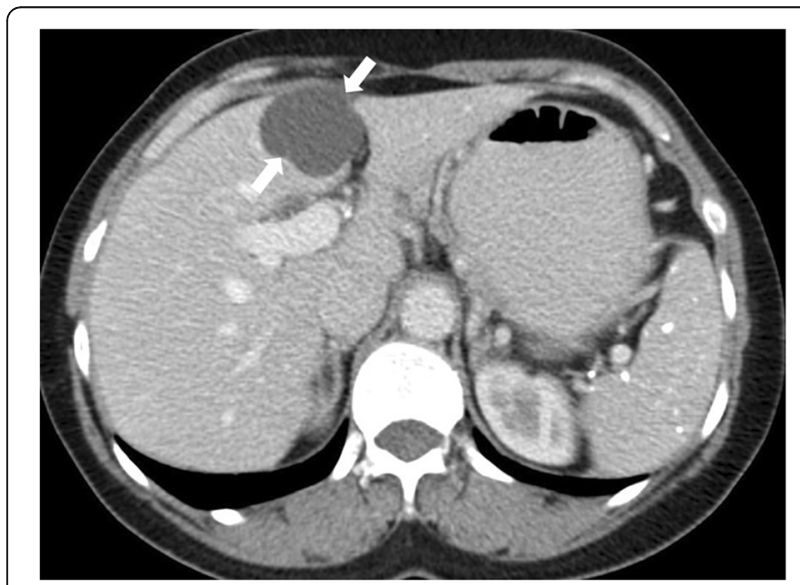

Fig. 12 A 40-year-old female patient with known breast cancer. Axial plane post-contrast CT image shows a unilocular cystic lesion located in the subcapsular area of the segment 4 (arrows). The location was found to be typical for CHFC. The cyst was stable on 2year follow-up study (not shown) typical hyperintensity on T2W MR images. Enhancement is typically not detected after contrast injection. Characteristic location is an important diagnostic clue for diagnosis as signal characteristics are not different from usual benign hepatic cysts.

\section{Kidney}

Autosomal dominant polycystic kidney disease

Autosomal dominant polycystic kidney disease (ADPKD) is a relatively common disease and occurs in approximately $1 / 1000$ individuals. This hereditary condition is largely inherited in autosomal dominant fashion. Most patients become hemodialysis dependent around the 5th to 7th decade of life [10].

The cysts appear as typically hypoechoic on the US and hypodense on non-contrast CT images (Fig. 13). MRI findings are typical on advanced-stage disease with a bright T2 signal. Despite the fact that most of the cysts have typical imaging findings, some cysts may demonstrate unusual signal characteristics due to proteinaceous content. MRI studies with subtraction images may be helpful in the mural and cavitary evaluation of these cysts [10].

In the early stages of the disease, the kidneys may appear as either normal kidneys to single or multiple cysts in one or both kidneys (Fig. 14). The cysts typically increase in size and number into adulthood and during the final stages of the disease the entire renal parenchyma may be replaced with the cysts. Epidemiological and molecular biological data demonstrate that patients with ADPKD bear an increased risk for renal cell cancer (RCC). But preoperative image-based diagnosis is often challenging because of the distortion of the renal parenchyma [10]. (Fig. 15). 

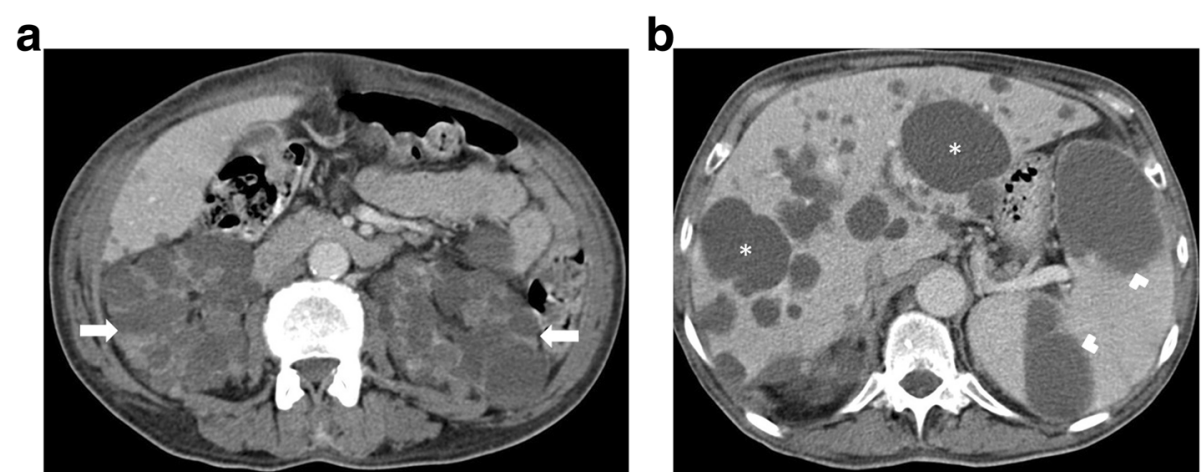

Fig. 13 A 63-year-old male patient with known ADPKD. a Axial plane post-contrast CT image shows enlarged kidneys with innumerable cysts (arrows). b More cranial CT image demonstrates multiple hepatic (asterisks) and splenic cysts (arrowheads)

\section{Autosomal recessive polycystic kidney disease}

Autosomal recessive polycystic kidney disease (ARPKD) is much less common than ADPKD and occurs in approximately one in 20.000 individuals [11]. The diagnosis is generally made in utero due to oligohydramnios from decreased fetal urine production. Severe renal dysfunction immediately after birth is typical. Abdominal distension due to enlarged kidneys, bilateral flank "masses", and/or abdominal distension are common clinical findings. Pulmonary hypoplasia and pneumothorax are also common. Congenital hepatic fibrosis, Caroli disease, and bile duct ectasia may also be detected as associating abnormalities [12].

The US is the most commonly used modality for diagnosis. Enlarged kidneys, with thickened parenchyma, is the typical finding. Renal medulla appears as hyperechoic due to the presence of several ectatic renal tubules, also called as microcysts [11]. Larger cysts (larger than $1 \mathrm{~cm}$ )

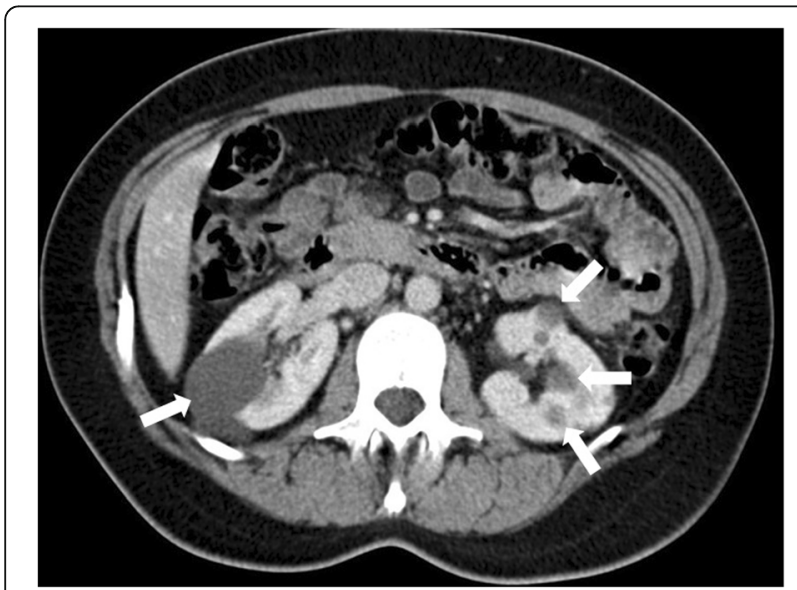

Fig. 14 A 34-year-old female patient with known hypertension and family history of ADPKD. Axial plane post-contrast CT image shows bilateral renal cysts with different sizes (arrows). Normal renal parenchyma can be seen. Genetic analysis confirmed the ADPKD may be seen in a certain subset of patients [13] (Fig. 16). With the advancement of the age, the cysts typically enlarge and may replace the renal parenchyma. On US studies, findings suggestive of hepatic abnormalities should also be sought after for early diagnosis and intervention. CT and MRI are rarely needed for diagnosis and IV contrast is not typically used due to limited renal reserve. Non-complicated cysts appear as hypodense on CT and T2 hyperintense on MR examinations (Fig. 17).

\section{Multicystic dysplastic kidney disease}

Multicystic dysplastic kidney (MCDK) is a congenital non-heritable cystic disease of the kidneys in the pediatric patient group. Renal cysts are formed in utero and may be observed on antenatal US examinations. The disease is typically unilateral and the affected kidney typically does not function [45].

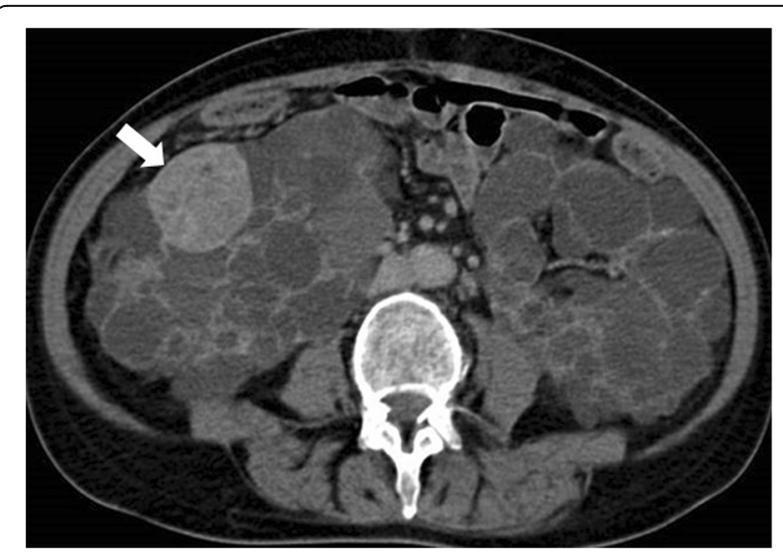

Fig. 15 A 56-year-old female patient with known ADPKD. Axial plane postcontrast CT image shows enlarged kidneys with innumerable cysts and a solid mass in the right kidney (arrow). Histopathological examination after surgery revealed papillary type renal cell carcinoma 

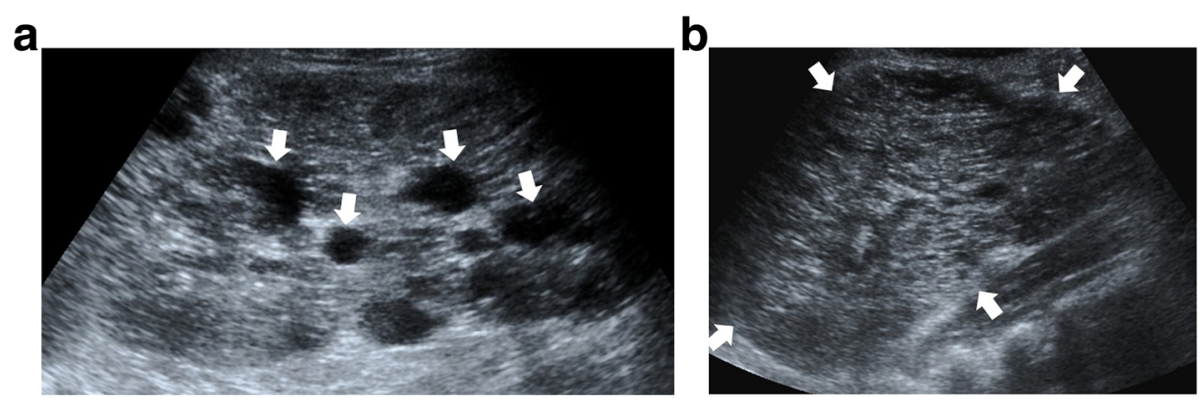

Fig. 16 A 3-year-old male patient known ARPKD. a Sagittal view US image shows an enlarged kidney with cortical and medullary hyperechogenicity due to small cysts. There are also bigger cysts in the kidney (arrows). b Axial plane US image of the liver shows contour irregularities and parenchymal heterogeneity (arrows) consistent with congenital hepatic fibrosis

The US is typically the imaging modality of choice in this patient group. The detection of renal cysts in a disorganized pattern is the typical imaging finding and renal parenchyma is characteristically completely replaced by these cysts [14] (Fig. 18). MRI demonstrates similar findings with the US exam (Fig. 19).

\section{Nephronophthisis and medullary cystic kidney disease}

Medullary cystic kidney disease and nephronophthisis, which are a common cause of end-stage renal disease during the first 3 decades of life, are inherited diseases with similar renal morphology and histopathologic features. The inheritance pattern is variable; nephronophthisis is autosomal recessive in inheritance and medullary cystic kidney disease is autosomal dominant [15]. Several other syndromes may be associated with nephronophthisis [46].

On US studies, the kidneys, contrary to ARPKD, appear small due to parenchymal fibrosis. Cysts, of varying

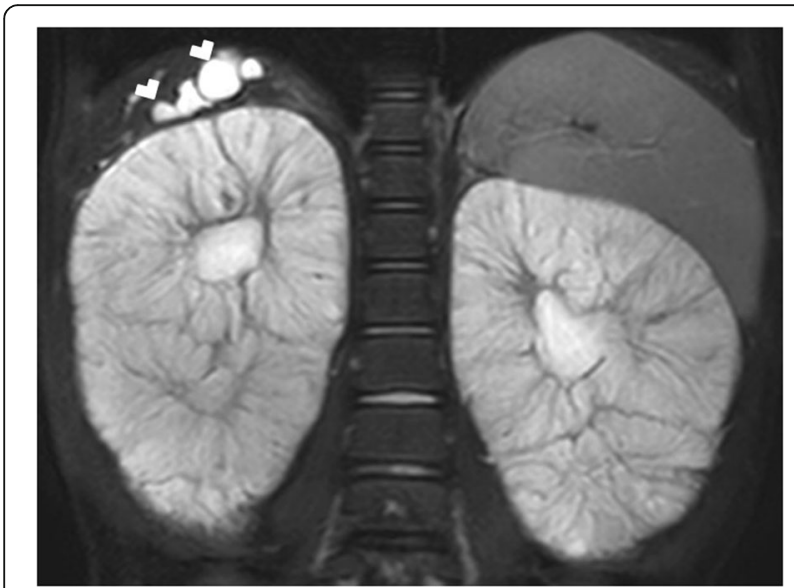

Fig. 17 A 5-year-old male patient with known ARPKD. Coronal plane T2W MR image shows enlarged kidneys with diffusely increased T2 signal. Also note subcentimeter liver cysts (arrowheads) size, in medullary and corticomedullary locations may be detected [15, 16] (Fig. 20). Early in life, it may be possible not to detect any cysts, the kidneys may appear hyperechoic with the loss of corticomedullary differentiation [47]. The cystic changes in the renal parenchyma are generally progressive and advance with age.

\section{Von Hippel-Lindau disease}

Von Hippel-Lindau (VHL) syndrome is a phakomatosis inherited in an autosomal dominant fashion. It is a rare disease which affects 17/36.000-53.000 individuals [48]. This syndrome predisposes the affected individual to different cancers.

Renal manifestations are common and renal cysts may be detected in $59-63 \%$ of patients and bilateral involvement is extremely common (around $75 \%$ of the cases) [17]. RCCs are also common and are seen in $24-45 \%$ of the affected individuals [49]. Periodic screening of the kidneys is mandatory as untreated RCCs carry a poor

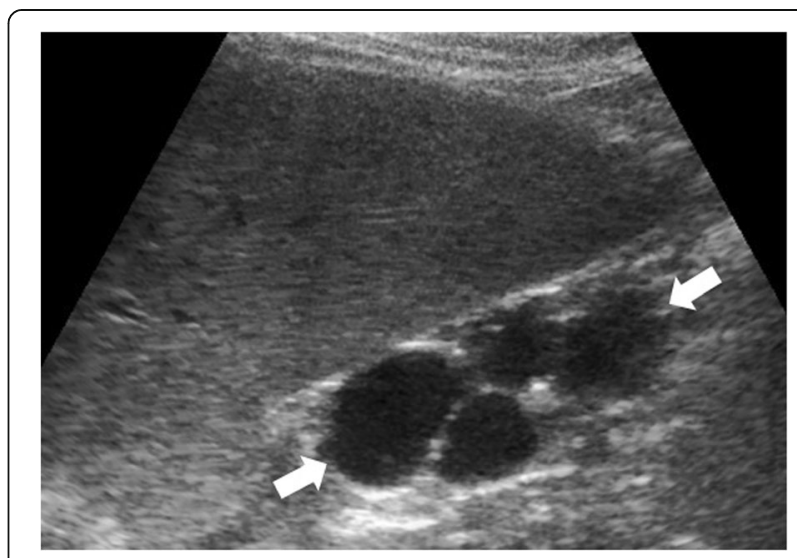

Fig. 18 Newborn with prenatally detected left kidney cysts underwent an US study on the first day of life. Sagittal view US image shows multiple cysts in the left renal fossa with no discernible normal renal parenchyma. The right kidney was normal (not shown). Imaging findings were found to be consistent with MCDK 


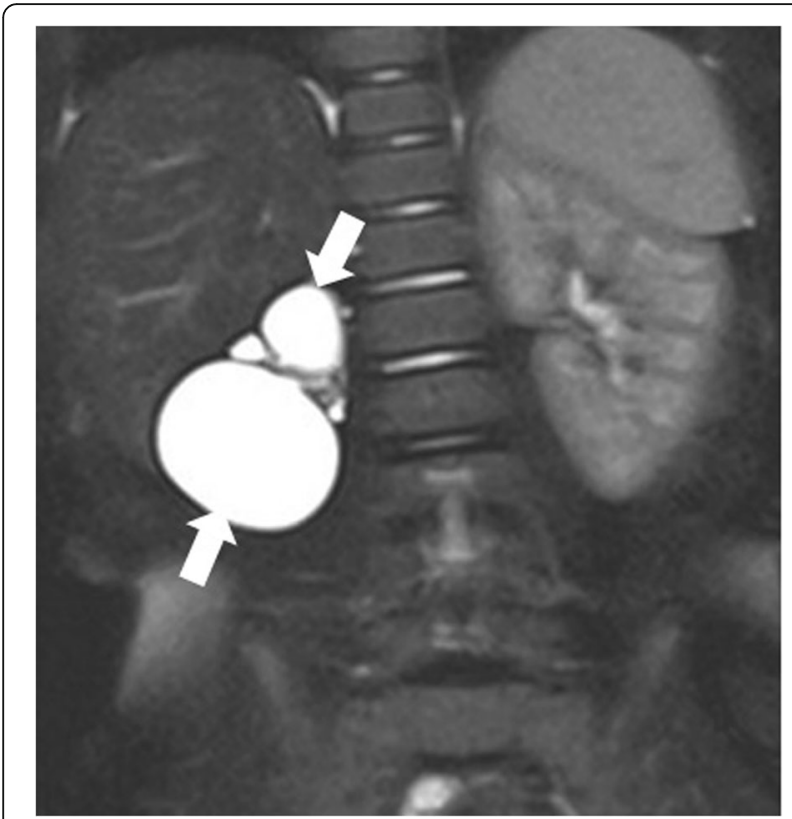

Fig. 19 A 12-day-old newborn with prenatally diagnosed right kidney cysts underwent an abdominal MRI examination. Coronal plane T2W MR image shows multiple cysts completely replacing the right kidney parenchyma (arrows). There was no discernible renal parenchyma aside from the cysts. The left kidney was normal

prognosis with a tendency to metastasize [18]. The histopathologic features of the renal cysts vary, ranging from simple and hyperplastic cysts to cystic clear cell carcinomas and to solid tumors [50]. All mentioned benign and malignant lesions may occur in the same

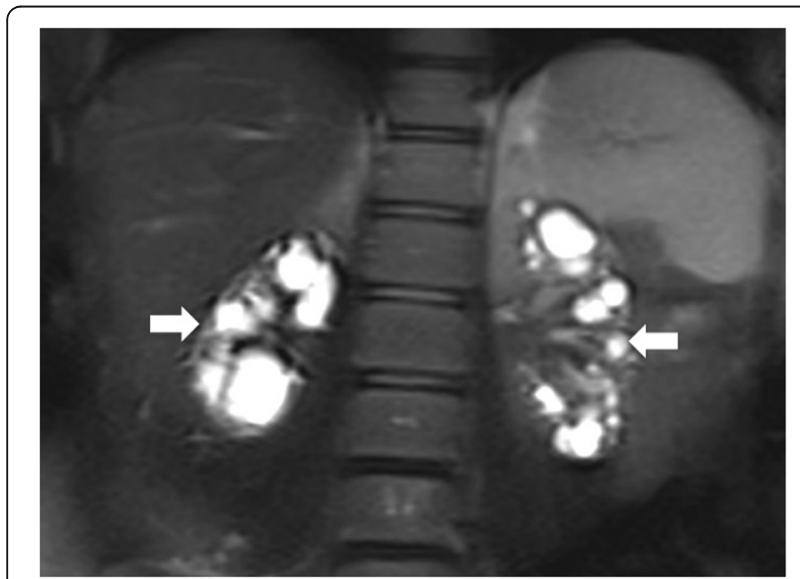

Fig. 20 A 13-year-old female patient with known histopathologically proven nephronophthisis now presenting with flank pain. The patient is on chronic hemodialysis. Coronal plane T2W MR image shows multiple cysts in both kidneys located at the corticomedullary junction. There was no discernible healthy renal parenchyma in the kidneys. Also note that both kidneys (arrows) are small in their overall sizes in contrast to ARPKD

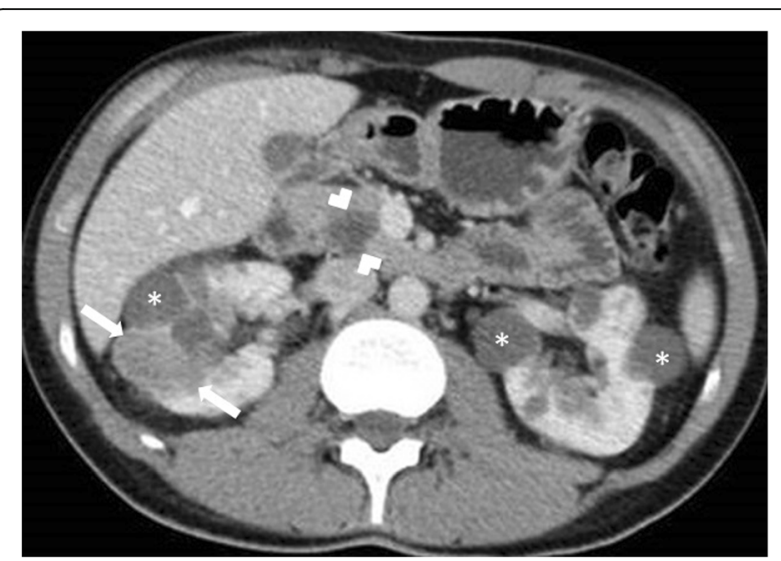

Fig. 21 A 43-year-old male patient with known VHL underwent a follow-up CT exam. Axial plane post-contrast $C T$ image shows several renal cysts (asterisks) in both kidneys. Also note is made of a new focus of clear cell RCC (surgically confirmed) in the right kidney (arrow). A pancreatic cyst in the uncinate process was also detected (arrowheads)

kidney at the same time. Tumors may arise from precursor cystic lesions or completely de novo [49]. Thus, continuous imaging screening is fundamental for early diagnosis and treatment to prevent metastatic disease. Cysts may enlarge or regress with time leaving parenchymal scars, and no relationship has been observed with the cyst size and number and the malignant potential [17].

The US may be helpful to differentiate the cysts from the solid masses but CT and MRI are more commonly used for both diagnosis and follow-up (Fig. 21). Mural nodules within the cyst walls are suggestive for cancer and they can be observed with relative ease on both CT and MRI. Pure solid lesions may also be assessed with these two modalities and renal vein involvement can also be detected. CT and MRI are more sensitive for detecting small lesions $(2 \mathrm{~cm})$ [49]. MRI might be preferable for follow-up purposes, especially in young patients, due to lack of radiation with this modality. Subtraction images may be helpful for differentiating proteinaceous cysts from solid masses. Due to the progressive course of VHL syndrome, partial nephrectomy and percutaneous ablative measures are common approaches for the treatment of RCCs in these patients.

\section{Tuberous sclerosis complex}

Tuberous sclerosis complex (TSC) disease affects around $1 / 5.000-10.000$ individuals [51]. TSC is typically inherited in an autosomal dominant fashion but the expression is variable. Around $66 \%$ of the cases are secondary to sporadic mutation. TSC is a multisystemic disease and may manifest with numerous mesodermal and ectodermal abnormalities. Kidneys are also affected along the course of the disease. Angiomyolipomas, with 


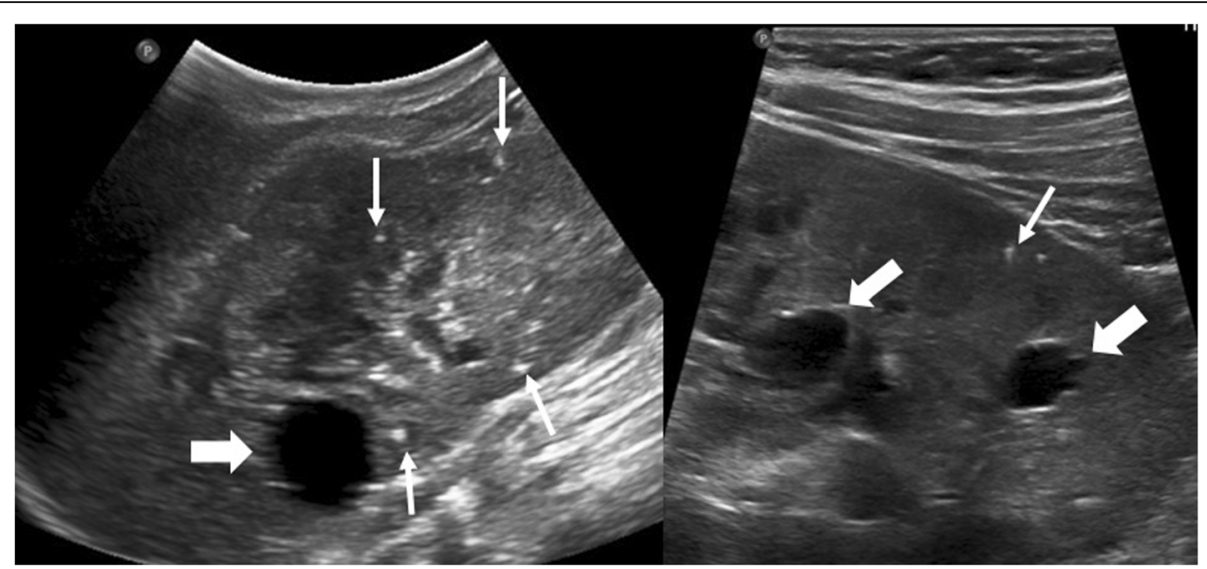

Fig. 22 A 9-year-old male patient with known TSC underwent follow-up US exam. US images show punctate hyperechoic foci consistent with subcentimeter angiomyolipomas (fine arrows). Also note is made of several parenchymal cysts (thick arrows)

variable fat content, and renal cysts are the two most common renal lesions in these patients [19]. Large angiomyolipomas may spontaneously rupture in the course of the disease, renal cysts are almost always asymptomatic [52]. Angiomyolipomas tend to be more numerous and common compared to renal cysts [19].

On imaging, renal cysts in TSC appear like simple renal cysts (Fig. 22). Differential diagnosis from ADPKD may be difficult as fewer cysts are typically seen at the early stage of this disease. The very common association of renal cysts with angiomyolipomas may serve as a reliable imaging clue for correct diagnosis. The cysts tend not to be large in size and the average diameter of these cysts was reported to be around $20 \mathrm{~mm}$ which may be another helpful clue considering the large sizes of the cysts in patients with ADPKD [19].

\section{Pancreas}

\section{Von Hippel-Lindau disease}

As VHL is a multisystemic disease, the pancreas may also be affected among the course of the disease. The pancreatic manifestations are either cysts, serous cystadenomas, or neuroendocrine tumors (NETs). Combined lesion pattern, the presentation of solid and cystic manifestations, may be observed in $11.5 \%$ of patients with VHL disease and in $7.6 \%$ of the cases pancreas may be the only affected organ [20].

The pancreatic cysts follow the typical imaging characteristics of cysts elsewhere in the body (Fig. 23). Pancreatic NETs are mostly solid but cystic tumors were also reported [21] (Fig. 24). These tumors, be it cystic or solid, generally tend to have early arterial phase-contrast enhancement for detection and correct characterization.
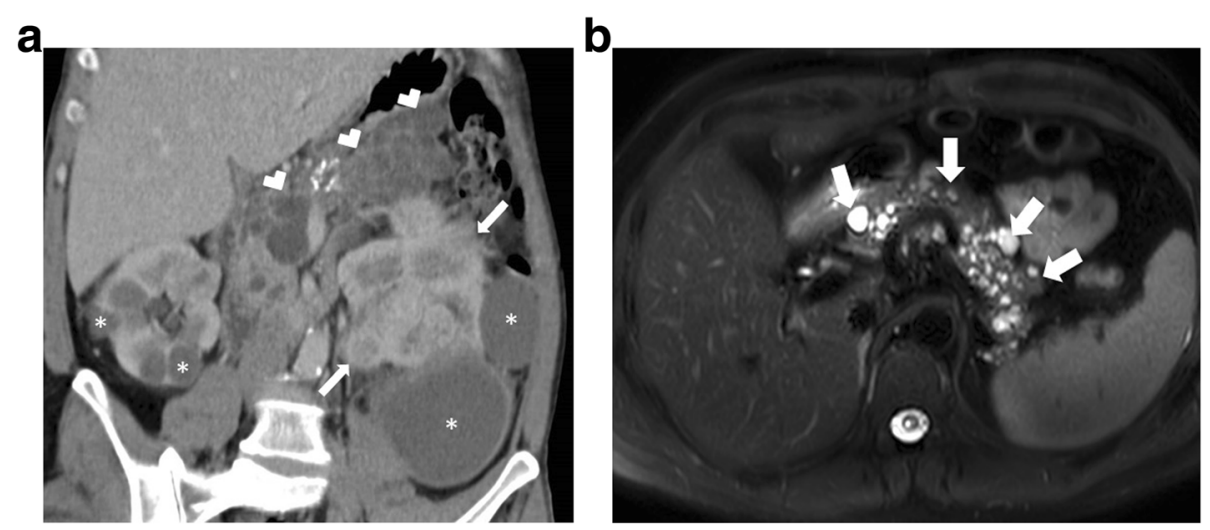

Fig. 23 Two different patients with VHL. a Coronal plane post-contrast CT image of a 47-year-old male patient shows innumerable pancreatic cysts (arrowheads). Also note is made of large-sized solid RCC (arrows) in the left kidney and bilateral renal cysts (asterisks). b Axial plane T2W MR image of a 40-year-old male patient demonstrates multiple cysts of the pancreas, almost completely replacing pancreatic parenchyma (arrows) 


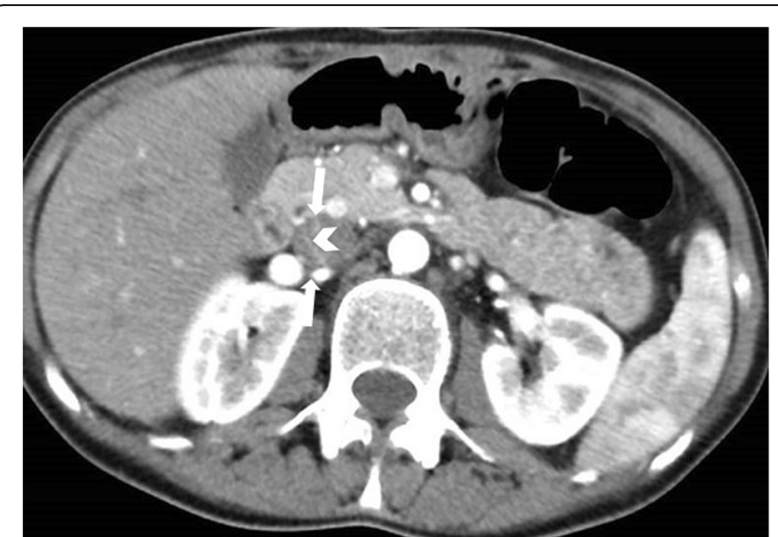

Fig. 24 A 21-year-old female patient with recently diagnosed (with genetic testing after a recent diagnosis of her elder sister) $\mathrm{VHL}$ underwent a baseline CT exam. Axial plane post-contrast pancreatic phase $C T$ image shows a predominantly cystic lesion in the uncinate process (arrows) with enhancing mildly thickened internal septation (arrowhead). The lesion was found to be highly suspicious of a cystic NET. Surgical removal and histopathological examination confirmed the presence of cystic NET

\section{Multiple endocrine neoplasia type I}

MEN 1 is an inherited endocrine tumor syndrome in autosomal dominant fashion. The pituitary gland, islet cells of the pancreas, and parathyroid glands are the most common tumor sites. Imaging plays an important role in the diagnosis and management of the disease [53].

Most pancreatic NETs in MEN 1 are functional with the gastrinoma being the most common [54]. The pancreatic NETs seen in MEN 1 follow the typical imaging

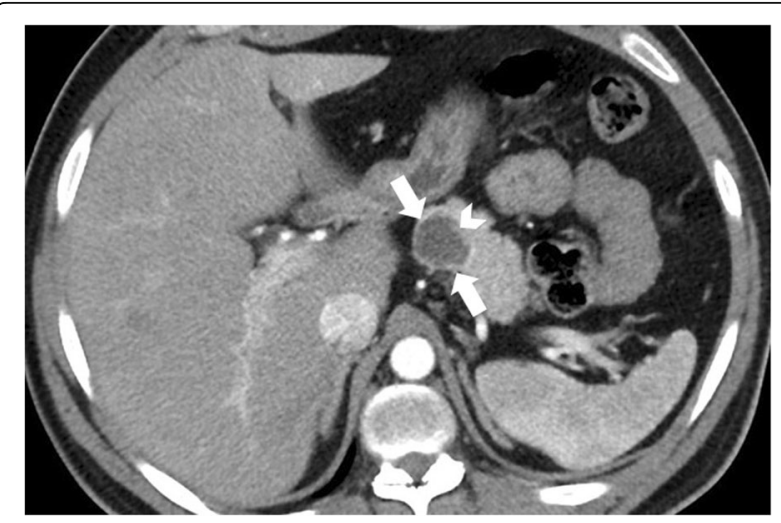

Fig. 25 A 31-year-old male patient with known MEN-1 syndrome underwent CT scanning to detect manifestations of the syndrome. Axial plane post-contrast pancreatic phase CT image shows a predominantly cystic lesion in the pancreatic body (arrows). Focal contrast-enhancing mural wall thickening can also be seen (arrowhead). Histopathological findings revealed cystic NET

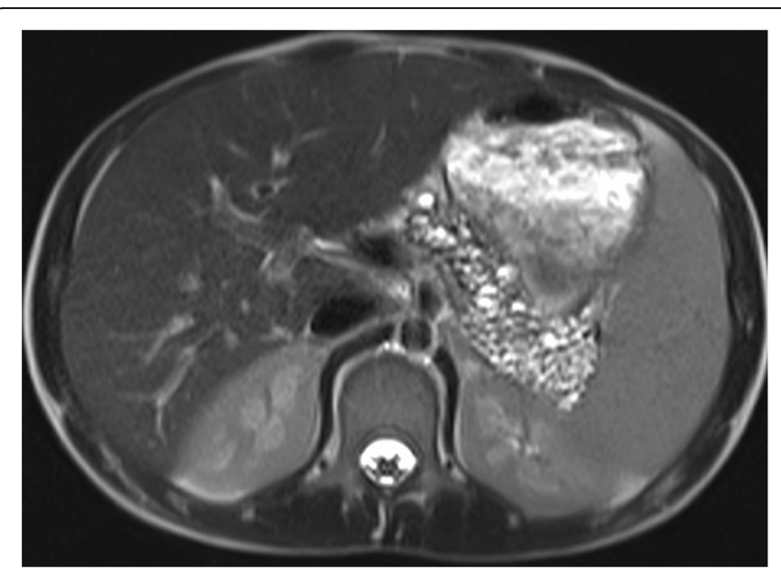

Fig. 26 A 13-year-old male patient with known CF and pancreatic insufficiency. Axial plane T2W MR image reveals innumerable cysts of subcentimeter size scattered throughout the pancreas, almost completely replacing the parenchyma (arrows)

characteristics of spontaneous NETs. Rarely, the tumors can be cystic [22] (Fig. 25).

\section{Cystic fibrosis}

Cystic fibrosis (CF) is a common hereditary systemic disease. Exocrine glands are commonly affected and pancreatic insufficiency is a common manifestation of the disease.

Four different imaging patterns were described in patients with CF: (1) partial fatty replacement of the pancreas, (2) complete fatty replacement of the pancreas, (3) atrophy of the pancreas, and (4) pancreatic cystosis. Among these four different patterns, pancreatic cystosis is the least common [55]. In pancreatic cystosis, the organ parenchyma is filled with macrocysts and the development of these cysts has been linked to bicarbonate transport [23].

On the US, the cysts appear as hypoechoic structures with no associating mural wall thickening and nodularity. The size of the cysts is variable ranging from $0.5 \mathrm{~cm}$ to $1.2 \mathrm{~cm}$ in diameter. Vascular displacement due to the mass effect of these cysts are may be seen [56]. MRI is also a very helpful modality to detect the cysts and their anatomic relationship, due to its high soft-tissue resolution (Fig. 26). Malignant transformation of these cysts has not reported before [57]. Polycystic kidney disease and VHL may be considered in differential diagnosis but detection of normal kidneys and patient history are generally diagnostic without any significant confusion.

\section{Gastrointestinal tract duplication cysts}

Gastrointestinal (GI) tract duplication cysts are rare congenital malformations which are typically detected in young patients and adults [58]. They may occur anywhere along the GI tract but distal ileum is the most 


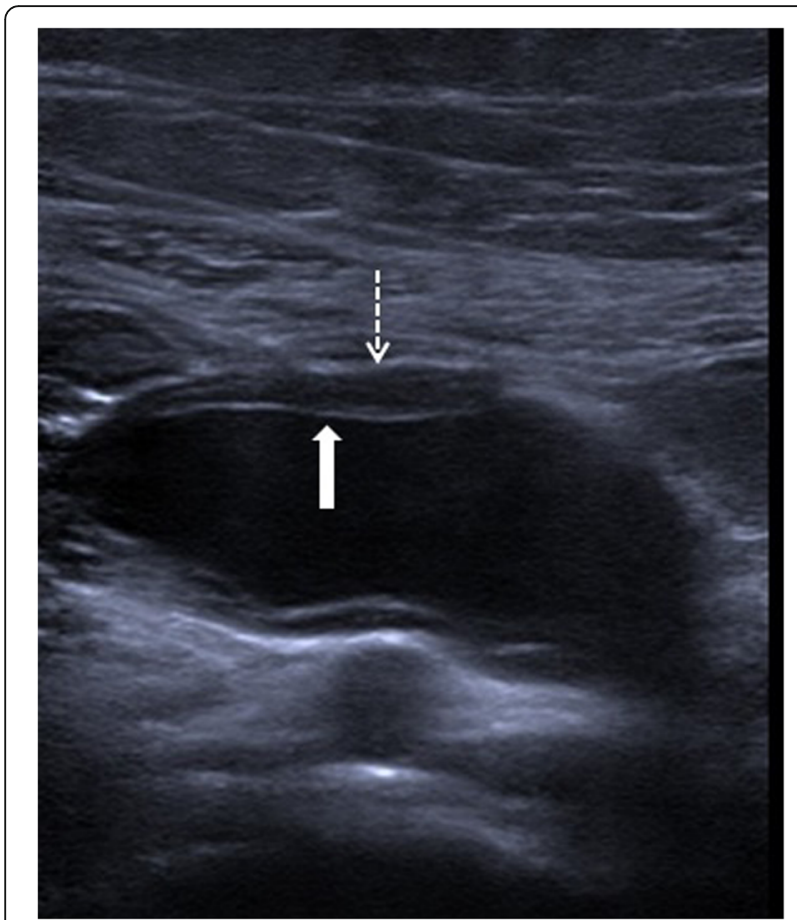

Fig. 27 An 8-year-old male patient presenting to the emergency department (ED) with right lower quadrant pain. Axial view US image shows a cystic mass with thick wall suggested for "doublewall" sign: The mucosa appears hyperechoic (arrow) whereas the muscular layer hypoechoic (dashed-line arrow). Laparoscopic surgery and histopathologic examination confirmed the ileal duplication cyst causing intestinal obstruction

commonly affected segment followed by the esophagus, colon, jejunum, stomach, and the duodenum [59]. These lesions may be contained within the wall of the affected segments but may also be detected extrinsic to the bowel segment and may appear as either spherical $(80 \%)$ or tubular cysts $(20 \%)[60,61]$. This morphologic difference may provide a clue regarding the possible communication between the enteric lumen and the duplication cysts, as the spheric ones generally do not communicate with the lumen, whereas, its tubular counterparts typically do.

Histopathologically, GI tract duplication cysts consist of an epithelial lining containing the mucosa of the GI tract and a surrounding smooth muscle. The cyst is also closely attached to the enteric wall [24].

GI tract duplication cysts are most commonly diagnosed incidentally but complications may also occur, including obstruction, volvulus, intussusception, bleeding, perforation, and infection. Malignant transformation from the mucosa is extremely rare and surgical resection is the preferred approach for treatment [59].

The US is the most commonly used imaging modality. The diagnosis is generally straightforward when the cyst within the close proximity of the bowel segment. The

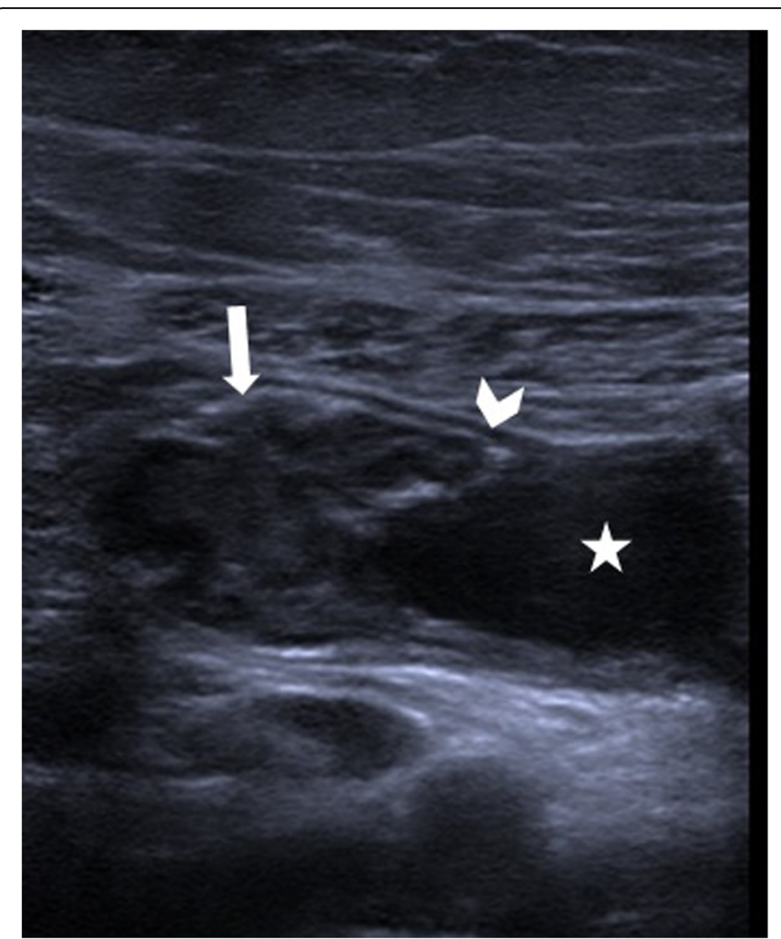

Fig. 28 A 7-year-old female patient presenting to ED with right lower quadrant pain. Axial view US image demonstrates a purely cystic mass (star) in the right lower quadrant. The wall of this lesion was in direct continuity (arrowhead) with the adjacent terminal ileum segment (arrow)

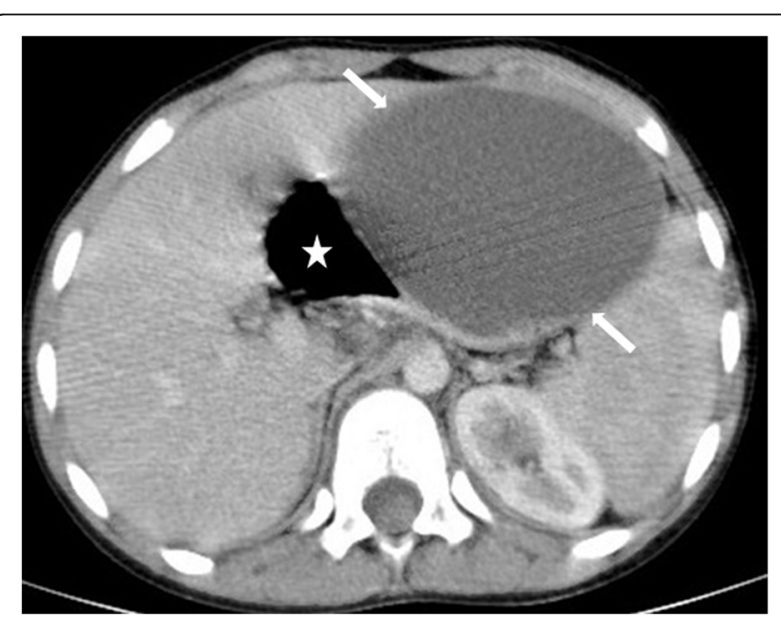

Fig. 29 A 9-year-old female patient with palpable epigastric mass was found to have a large cystic mass in the epigastrium on US examination (not shown). An abdominal CT study was planned for better assessment of the anatomic relationship of this lesion. Axial plane post-contrast CT image shows a huge cystic mass (arrows) compressing and displacing the stomach (star). Surgery confirmed gastric duplication cyst 
double-wall or muscular rim sign is the typical imaging finding (Fig. 27). This imaging appearance is due to the inner hyperechoic mucosa and the surrounding hypoechoic smooth muscle layer (muscularis propria) [24]. The GI tract duplication cysts share a common wall with the adjacent gut segment. The so-called "Y configuration" is a helpful diagnostic sign that is indicative of a shared wall with the cyst and the neighboring bowel wall (Fig. 28). This sign is caused by the splitting of the shared muscularis propria with the cyst and bowel wall $[25,26]$. Due to the presence of smooth muscle content, these cysts may change shape due to muscular contractions of the cyst wall, which is another useful finding for diagnosis on real-time sonographic examination [58]. The cysts are generally homogenous on the sonographic exam; however, internal septations or luminal debris may also be observed in certain patients. Color Doppler US exam may be helpful to detect wall inflammation in complicated duplication cysts [24].

CT and MRI are not typically used for diagnosis due to ionizing radiation and increased patient cooperation, consecutively. However, these modalities may be used for better assessing the anatomical relations of duplication cysts (Fig. 29). They can also be used in patients with questionable malignant degeneration within these cysts.

\section{Abdominal lymphatic malformations}

Abdominal lymphatic malformations (LMs) are rare congenital malformations of the lymphatic system. They are most commonly located in the small bowel

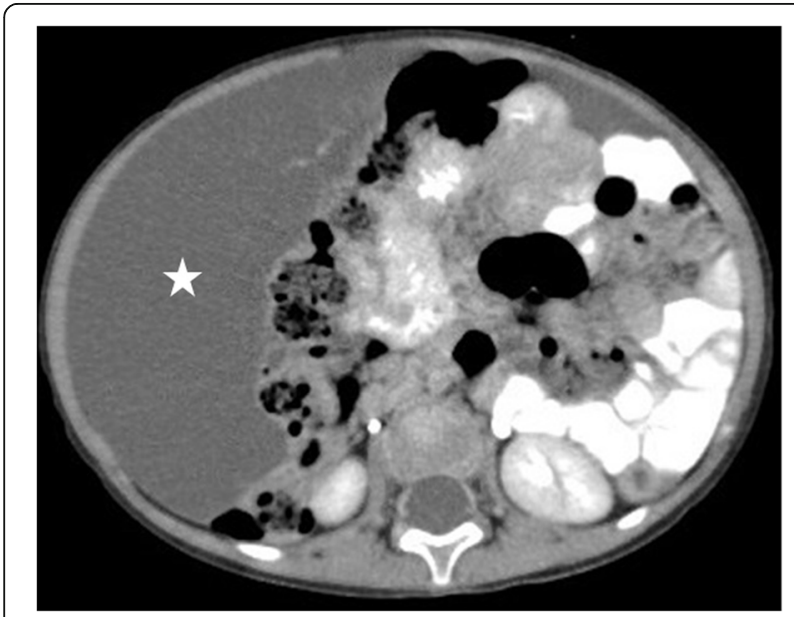

Fig. 30 A 1-year-old male patient presented with progressively enlarging abdominal girth. Axial plane CT image after IV and oral contrast use shows a large purely cystic mass (star), displacing the bowel loops to the left side of the abdomen. Histopathological examination after surgical extirpation confirmed omental lymphangioma

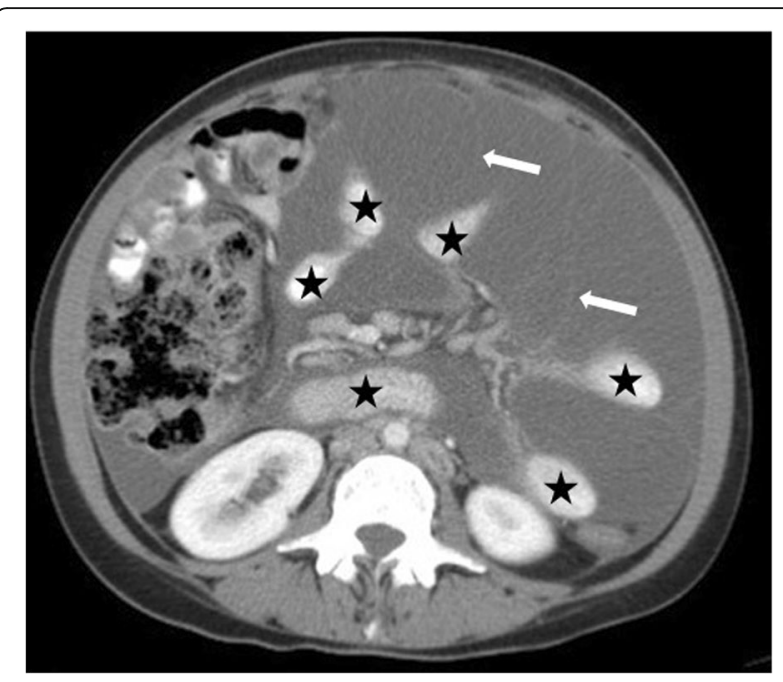

Fig. 31 A 39-year-old female patient with progressive abdominal distension underwent an US exam which showed large volume ascites in the abdomen. The clinical and imaging findings were concerning for peritoneal carcinomatosis. Axial plane CT image after IV and oral contrast use reveals a large cystic lesion insinuating between the mesenteric leaves. This cystic mass was separating apart the adjacent bowel loops (stars). Also noted were internal septations (arrows) within this large cystic mass. Surgical and subsequent histopathological examinations confirmed large mesenteric lymphangioma.

mesentery, followed by omentum, mesocolon, and retroperitoneum [62]. Abdominal LMs are rare as LMs are most commonly located in the head-neck region [63]. LMs are generally small in size and most commonly diagnosed incidentally on imaging but symptoms may occur, including abdominal pain or distension, particularly in large size LMs. Asymptomatic LMs do not require treatment and can be followed with serial imaging. The common approach for the treatment of symptomatic LMs is surgical resection $[27,64,65]$.

US and CT are the two most commonly used modalities for diagnosis. The anatomic relations of these cystic masses and their internal contents may be assessed with high precision with both techniques (Fig. 30). Ascites may be confused with these LMs but well-circumscribed morphology, as opposed to free-floating ascites, favors LMs over ascites. However, LMs may also conform to omental anatomy and differential diagnosis from loculated ascites may be difficult in certain cases (Fig. 31). The fluid in the LMs may contain fat which may be better appreciated on CT or MRI studies [28] (Fig. 32). Small LMs are frequently mobile and, therefore, they can be observed in different locations on separate follow-up imaging studies [27]. 


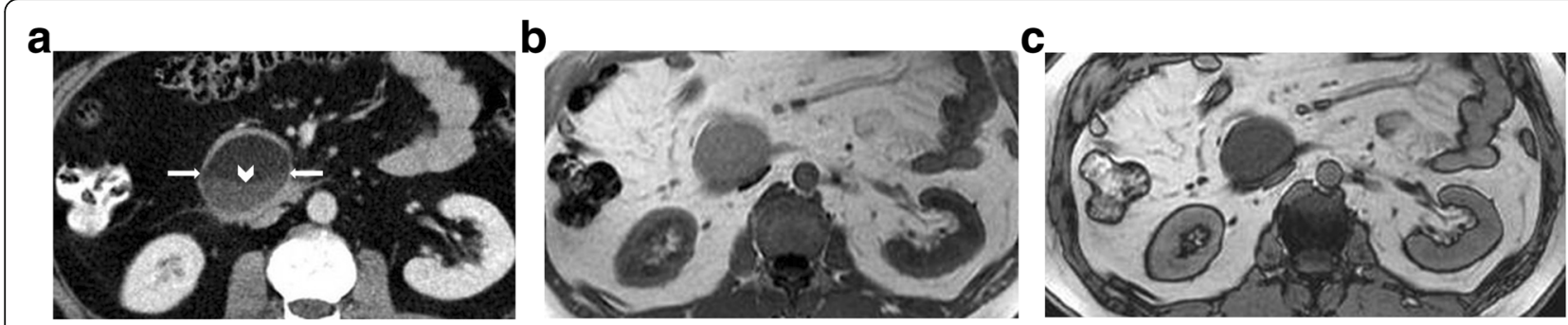

Fig. 32 A 41-year-old female patient with newly diagnosed breast cancer underwent a staging body CT examination. a Axial plane post-contrast CT image shows a well-circumscribed retroperitoneal mass (arrows) with a fat-fluid level (arrowhead). b, c Abdominal MRI exam of the same patient showed signal loss within the cyst content on out-of-phase image (c) compared to in-phase image (b). Imaging findings were found to be compatible with chylous fluid containing lymphangioma. Follow-up imaging studies confirmed the stability of this lesion

\section{Diaphragm}

\section{Diaphragmatic mesothelial cyst}

Diaphragmatic mesothelial cysts (DMC) are derived from coelomic remnants and are lined with mesothelial cells [66]. Mesothelial cysts may be found in several places including the diaphragm. Due to its close proximity of DMCs to liver, lung, and pleura, it may be difficult to determine the diaphragm as the source organ.

On imaging, they have characteristic findings of an ordinary cyst located elsewhere in the body. The walls of these cysts are thin with no associating solid component. They may also appear as bilobulated on sonography [29]. On the US, they appear as homogenously hypoechoic lesions located between the posterolateral aspect of the right liver lobe and the adjacent diaphragm (Fig. 33). CT and MRI may also be used as confirmatory studies. In these studies, internal content of the lesion may be better appreciated. Bronchogenic cysts, hydatid cysts, or an ordinary liver cyst may be considered in differential diagnosis. Bilobulated morphology of the cyst is an important clue for

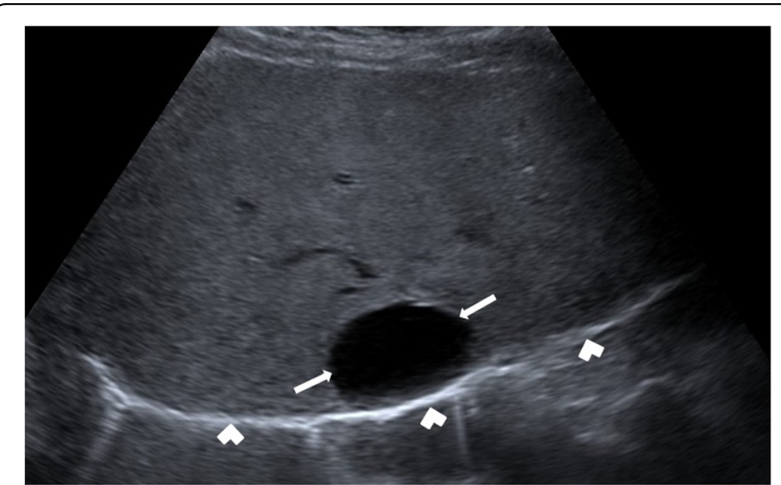

Fig. 33 A 23-year-old female patient with recently diagnosed hepatitis B infection underwent an initial liver US exam. Axial view US image shows a oval-shaped purely cystic lesion (arrows) in the posterolateral aspect of the right liver lobe in close proximity to the right hemidiaphragm (arrowheads). The lesion was found to be representing a diaphragmatic mesothelial cyst. Follow-up studies confirmed the stability of this lesion the diaphragmatic origin of the cyst [67]. These cysts may be effectively treated with a percutaneous approach [29].

\section{Prostate}

Prostatic utricle cyst-Mullerian duct cyst

Unlike paramedian ejaculatory ductus cysts, prostatic utricle and Mullerian duct cysts are two different cystic entities which are both located midline [68]. Prostatic utricle cysts may be associated with several genitourinary abnormalities [30]. On the contrary, Mullerian duct cysts are not expected to associate with any congenital genitourinary malformations. Both cysts may manifest with various symptoms, including difficulty urinating, dysuria, ejaculatory impairment, and hematospermia [31, 69]. In these cystic lesions, the mechanism of hematospermia is considered to be due to ejaculatory duct obstruction [68].

Differentiation of these entities by imaging alone may be difficult. Typically, prostatic utricle cysts do not

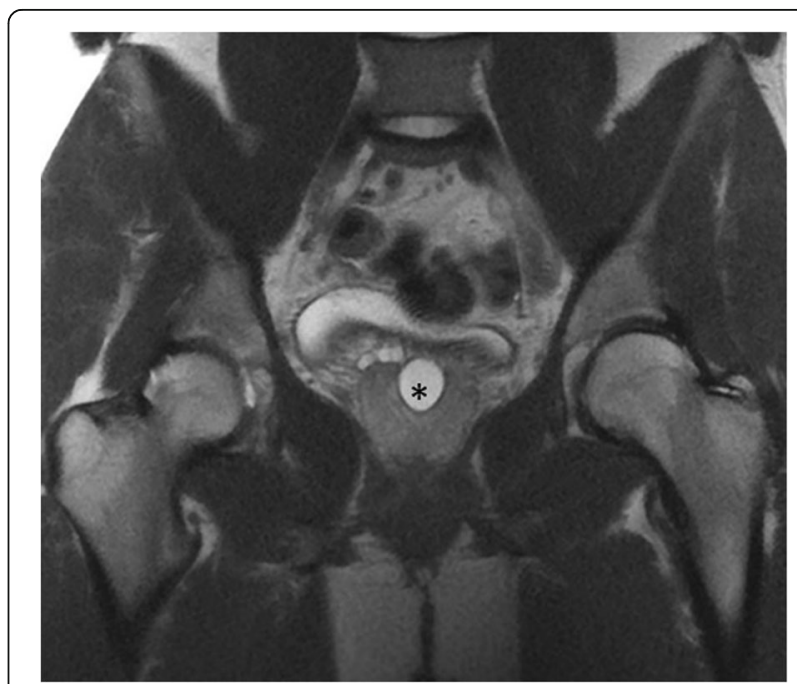

Fig. 34 A 17-year-old male patient with urinary incontinence. Coronal plane T2W MR image shows a midline prostatic cyst (asterisk) that does not extend above the prostate gland 


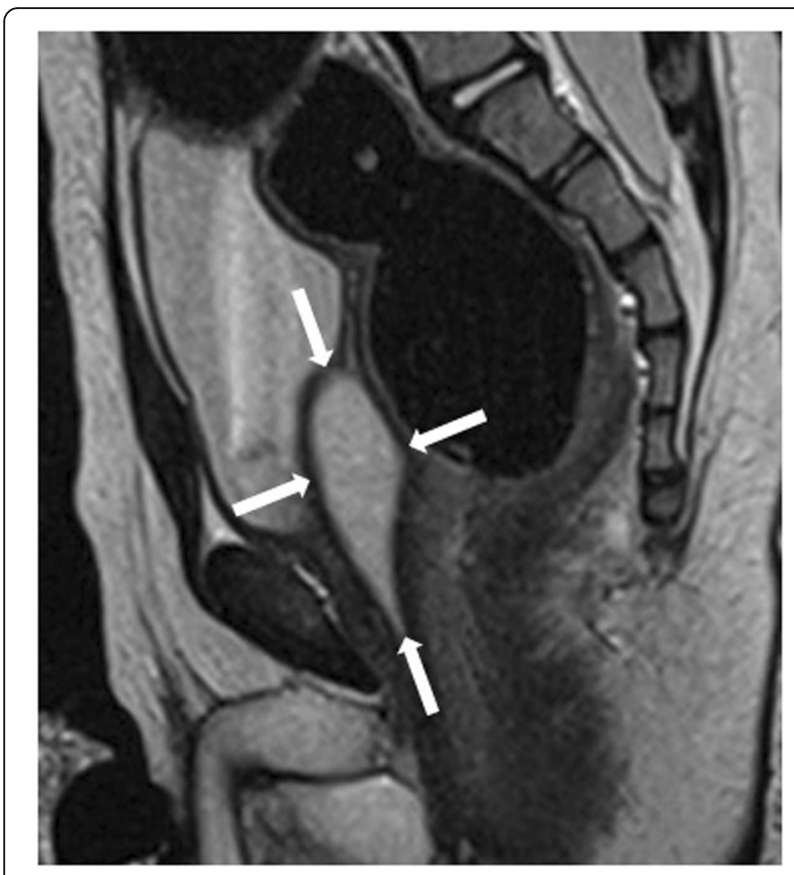

Fig. 35 A 2-year-old male patient with recurrent urinary tract infection underwent a US exam and a midline cystic lesion was seen posterior of the bladder (not shown). Confirmatory MRI exam shows a tear-drop shaped midline cystic lesion (arrows) on the sagittal plane T2W image. The cystic lesion was extending above the posterior superior margin of the prostate, highly suggestive for the Mullerian duct cyst

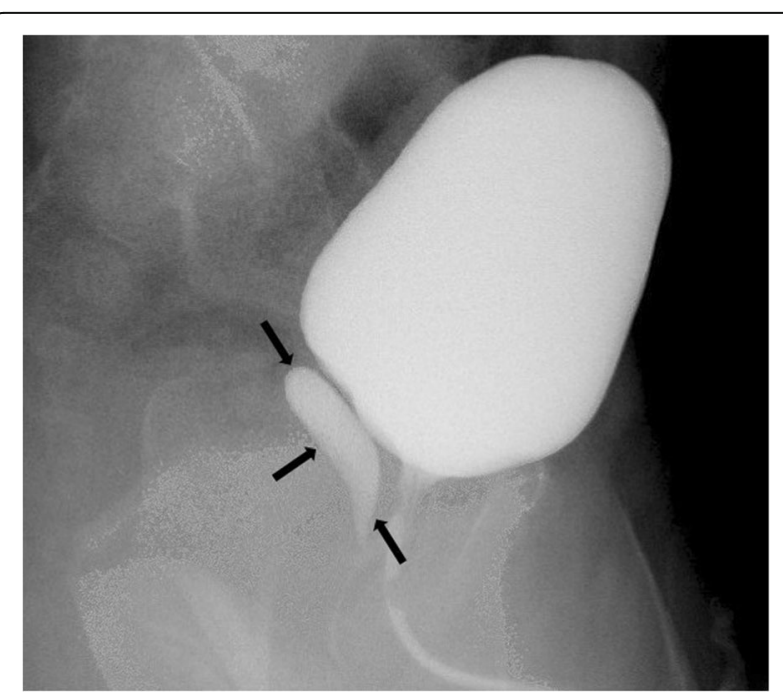

Fig. 36 A 5-year-old male patient with recurrent urinary tract infection. Voiding cystourethrogram demonstrates a contrast filling prostatic utricle cyst (arrows)

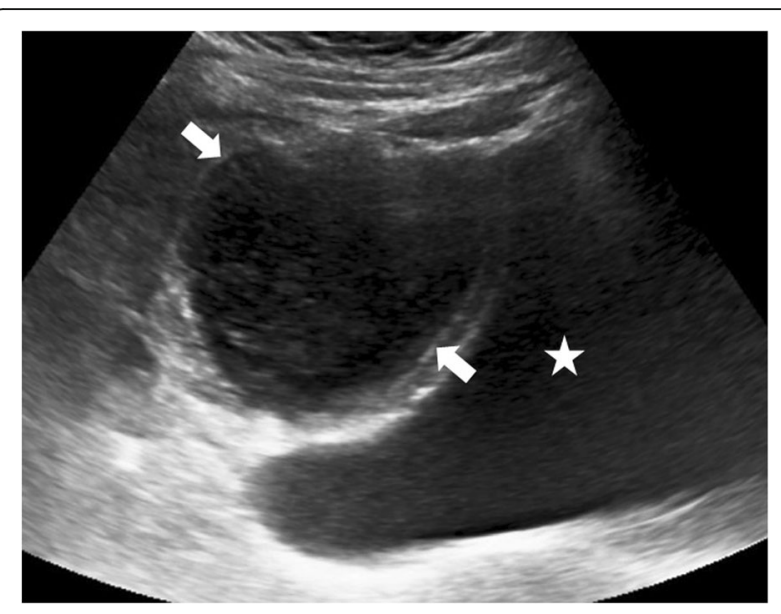

Fig. 37 A 6-year-old female patient presenting to ED with suprapubic pain. Sagittal view US image shows a round-shaped cystic lesion (arrows) above the superior surface of the bladder (star). Due to the mixed echogenicity of the lesion, it was considered an infected urachal cyst. Surgical findings confirmed the diagnosis

extend above the base of the prostate (Fig. 34), whereas Mullerian duct cysts are characteristically observed as teardrop-shaped midline cysts extending above the superior margin of the prostate (Fig. 35). In terms of size, prostatic utricle cysts are typically smaller than Mullerian duct cysts. From an anatomical standpoint, prostatic utricle cysts communicate with the prostatic urethra unlike Mullerian duct cyst [31, 68, 69]. Voiding cystourethrography may help differential diagnosis by demonstrating the connection between the prostatic utricle cyst and the urethra [70] (Fig. 36).

\section{Urachal cyst}

The urachus is a ductal remnant that originates from the involution of the allantois and cloaca. It extends from the bladder dome to the umbilicus. In the late stages of gestation, it involutes and obliterates and observed as a median umbilical ligament in the postgestational period. The failure of this mentioned involution may result in persistent of this canal after birth. The most common types of this failed involution are patent urachus and urachal cyst [71].

Urachal cysts form when both the umbilical and bladder ends of the urachus are obliterated with nonobliterated segment in between. These urachal cysts are typically small and asymptomatic; however, infection of the cysts may cause symptoms [32, 71].

On imaging, the diagnosis of an uncomplicated cyst may be easily made by detecting the cyst in the midline along the trajectory of the urachus. The detection of inhomogeneous cyst content and inflammatory stranding adjacent to the cyst may indicate infection [32] (Fig. 37). 


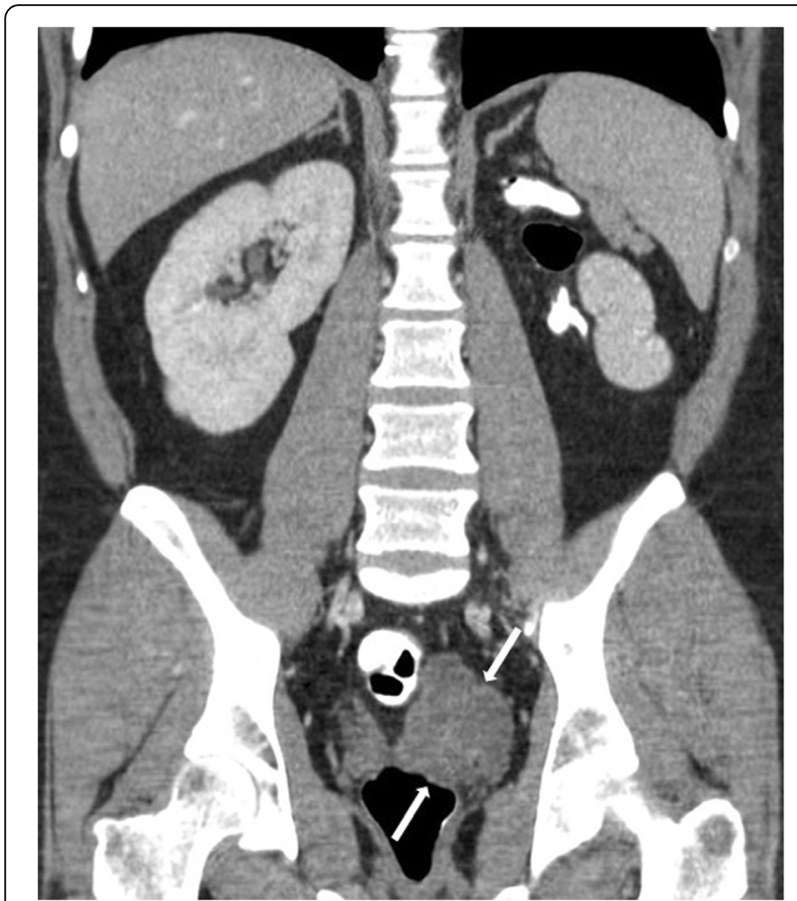

Fig. 38 A 31-year-old male patient presenting with left groin pain. Coronal plane postcontrast $C T$ image demonstrates left renal agenesis and left seminal vesicle cysts (arrows)

\section{Zinner's syndrome}

Zinner's syndrome is a rare developmental anomaly. It refers to the triad of ipsilateral ejaculatory duct obstruction, seminal vesicle cysts, and renal agenesis. The patients usually admit to the hospital with genitourinary symptoms in the 2nd-3rd decades of their life [72].

On imaging, the obstructed ejaculatory ducts are seen as tubular structures in the pelvis and the ipsilateral kidney is typically agenetic (Fig. 38). The content of ejaculatory ducts is characteristically anechoic on the US and homogenously hyperintense on T2W MR images. In the case of hemorrhage or infection, the duct content may appear as bright on T1W MR images. The detection of the tail-like connection between the cystic tubules and the seminal vesicle may indicate that the seminal vesicle is the site of origin [33].

\section{Conclusion}

Congenital and hereditary cystic lesions of the abdomen are relatively rare. They may be diagnosed incidentally or may give rise to symptoms which prompt their diagnosis. Correct diagnosis is critical as they may simulate several other benign and malignant acquired diseases of the abdomen, all of which have very different treatment approaches and prognostic implications. With the correct and appropriate use of imaging, with relevant clinical information and patient history, diagnosis may be relatively straightforward and clinical management may be implemented appropriately.

\begin{abstract}
Abbreviations
ADPKD: Autosomal dominant polycystic kidney disease; ARPKD: Autosomal recessive polycystic kidney disease; CD: Caroli disease; CF: Cystic fibrosis; CHFC: Ciliated hepatic foregut cyst; CT: Computed tomography;

DMC: Diaphragmatic mesothelial cyst; ED: Emergency department;

Gl: Gastrointestinal; LI-RADS v2018: Liver Imaging Reporting and Data System Version 2018; LM: Lymphatic malformation; MCDK: Multicystic dysplastic kidney; MEN1: Multiple endocrine neoplasia type I; MR: Magnetic resonance; MRCP: Magnetic resonance cholangiopancreatography; NET: Neuroendocrine tumor; PKD: Polycystic kidney disease; PLD: Polycystic liver disease;

RCC: Renal cell cancer; T1W: T1-weighted; T2W: T2-weighted; TSC: Tuberous sclerosis complex; US: Ultrasonography; VHL: von Hippel-Lindau; VMC: Von Meyenburg complex
\end{abstract}

\section{Authors' contributions}

ADK wrote the manuscript. SA collected the data and contributed to the writing of the text. $\mathrm{DA}, \mathrm{MO}, \mathrm{MH}$, and $\mathrm{BO}$ contributed to the writing of the text and edited the text. The authors read and approved the final manuscript. MK edited the text and first proposed the idea of writing this manuscript.

\section{Funding}

Not applicable.

\section{Availability of data and materials}

Data sharing is not applicable to this article as no datasets were generated or analyzed during the current study.

\section{Ethics approval and consent to participate} Not applicable.

\section{Consent for publication \\ Not applicable.}

\section{Competing interests}

The authors declare that they have no competing interests.

Received: 10 May 2020 Accepted: 16 July 2020

Published online: 05 August 2020

\section{References}

1. Borhani AA, Wiant A, Heller MT (2014) Cystic hepatic lesions: a review and an algorithmic approach. AJR Am J Roentgenol 203(6):1192-1204

2. Mamone G, Carollo V, Cortis K, Aquilina S, Liotta R, Miraglia R (2019) Magnetic resonance imaging of fibropolycystic liver disease: the spectrum of ductal plate malformations. Abdom Radiol (NY) 44(6):2156-2171

3. Arnold HL, Harrison SA (2005) New advances in evaluation and management of patients with polycystic liver disease. Am J Gastroenterol 100(11):2569-2582

4. Cannella R, Giambelluca D, Diamarco M et al (2020) Congenital cystic lesions of the bile ducts: imaging-based diagnosis. Curr Probl Diagn Radiol 49(4):285-293

5. Santiago IS, Loureiro R, Curvo-Semedo L et al (2012) Congenital cystic lesions of the biliary tree. AJR Am J Roentgenol 198(4):825-835

6. Todani T, Watanabe Y, Narusue M, Tabuchi K, Okajima K (1977) Congenital bile duct cysts: classification, operative procedures, and review of thirtyseven cases including cancer arising from choledochal cyst. Am J Surg 134(2):263-269

7. Maher MM, Dervan P, Keogh B, Murray JG (1999) Bile duct hamartomas (von Meyenburg complexes): value of MR imaging in diagnosis. Abdom Imaging 24(2):171-173

8. Lev-Toaff AS, Bach AM, Wechsler RJ, Hilpert PL, Gatalica Z, Rubin R (1995) The radiologic and pathologic spectrum of biliary hamartomas. AJR Am J Roentgenol 165(2):309-313

9. Ansari-Gilani K, Modaresi EJ (2017) Ciliated hepatic foregut cyst: report of three cases and review of imaging features. Gastroenterol Rep (Oxf) 5(1):7578 
10. Jilg CA, Drendel V, Bacher J et al (2013) Autosomal dominant polycystic kidney disease: prevalence of renal neoplasias in surgical kidney specimens. Nephron Clin Pract 123(1-2):13-21

11. Dillman JR, Trout AT, Smith EA, Towbin AJ (2017) Hereditary renal cystic disorders: imaging of the kidneys and beyond. Radiographics 37(3):924-946

12. Capisonda R, Phan V, Traubuci J, Daneman A, Balfe JW, Guay-Woodford LM (2003) Autosomal recessive polycystic kidney disease: outcomes from a single-center experience. Pediatr Nephrol 18(2):119-126

13. Avni FE, Guissard G, Hall M, Janssen F, DeMaertelaer V, Rypens F (2002) Hereditary polycystic kidney diseases in children: changing sonographic patterns through childhood. Pediatr Radiol 32(3):169-174

14. Gimpel C, Avni EF, Breysem L et al (2019) Imaging of kidney cysts and cystic kidney diseases in children: An international working group consensus statement. Radiology 290(3):769-782

15. Hildebrandt F, Waldherr R, Kutt R, Brandis M (1992) The nephronophthisis complex: clinical and genetic aspects. Clin Investig 70(9):802-808

16. Garel LA, Habib R, Pariente D, Broyer M, Sauvegrain J (1984) Juvenile nephronophthisis: sonographic appearance in children with severe uremia. Radiology 151(1):93-95

17. Leung RS, Biswas SV, Duncan M, Rankin S (2008) Imaging features of von Hippel-Lindau disease. Radiographics 28(1):65-79

18. Levine E, Lee KR, Weigel JW, Farber B (1979) Computed tomography in the diagnosis of renal carcinoma complicating Hippel-Lindau syndrome. Radiology 130(3):703-706

19. Casper KA, Donnelly LF, Chen B, Bissler JJ (2002) Tuberous sclerosis complex: renal imaging findings. Radiology 225(2):451-456

20. Ayloo S, Molinari M (2016) Pancreatic manifestations in von Hippel-Lindau disease: a case report. Int J Surg Case Rep 21:70-72

21. Hammel PR, Vilgrain V, Terris B et al (2000) Pancreatic involvement in von Hippel-Lindau disease. Gastroenterology 119(4):1087-1095

22. Sheth S, Hruban RK, Fishman EK (2002) Helical CT of islet cell tumors of the pancreas: typical and atypical manifestations. AJR Am J Roentgenol 179(3):725730

23. Taylor CJ, Aswani N (2002) The pancreas in cystic fibrosis. Paediatr Respir Rev 3(1):77-81

24. Sanguesa Nebot C, Llorens Salvador R, Carazo Palacios E, Pico Aliaga S, Ibanez PV (2018) Enteric duplication cysts in children: varied presentations, varied imaging findings. Insights Imaging 9(6):1097-1106

25. Kumar D, Ramanathan S, Haider E, Khanna M, Otero C (2015) Education and imaging. gastroenterology: revisiting the forgotten sign: five layered gut signature and $Y$ configuration in enteric duplication cysts on high resolution ultrasound. J Gastroenterol Hepatol 30(7):1111

26. Tritou I, Sfakianaki E, Prassopoulos P (2015) The sonographic multilaminar appearance is not enough for the diagnosis of enteric duplication cyst in children. AJR Am J Roentgenol 204(2):W222-W223

27. McEwing R, Hayward C, Furness M (2003) Foetal cystic abdominal masses. Australas Radiol 47(2):101-110

28. Yoo E, Kim MJ, Kim KW, Chung JJ, Kim SH, Choi JY (2006) A case of mesenteric cystic lymphangioma: fat saturation and chemical shift MR imaging. J Magn Reson Imaging 23(1):77-80

29. Akinci D, Akhan O, Ozmen M, Ozkan OS, Karcaaltincaba M (2005) Diaphragmatic mesothelial cysts in children: radiologic findings and percutaneous ethanol sclerotherapy. AJR Am J Roentgenol 185(4):873-877

30. Nghiem HT, Kellman GM, Sandberg SA, Craig BM (1990) Cystic lesions of the prostate. Radiographics 10(4):635-650

31. Mittal PK, Camacho JC, Sahani DV et al (2016) Hematospermia evaluation at MR imaging. Radiographics 36(5):1373-1389

32. Yu J-S, Kim KW, Lee H-J, Lee Y-J, Yoon C-S, Kim M-J (2001) Urachal remnant diseases: spectrum of CT and US findings. Radiographics 21(2):451-461

33. Mehra S, Ranjan R, Garga UC (2016) Zinner syndrome-a rare developmental anomaly of the mesonephric duct diagnosed on magnetic resonance imaging. Radiol Case Rep 11(4):313-317

34. Everson GT, Taylor MR, Doctor RB (2004) Polycystic disease of the liver. Hepatology 40(4):774-782

35. Qian Q (2010) Isolated polycystic liver disease. Adv Chronic Kidney Dis 17(2): 181-189

36. Cnossen WR, Drenth JP (2014) Polycystic liver disease: an overview of pathogenesis, clinical manifestations and management. Orphanet J Rare Dis 9:69
37. Brancatelli G, Federle MP, Vilgrain V, Vullierme MP, Marin D, Lagalla R (2005) Fibropolycystic liver disease: $C T$ and MR imaging findings. Radiographics 25(3):659-670

38. Abdel Razek AAK, El-Serougy LG, Saleh GA, Shabana W, Abd E-WR (2020) Liver Imaging Reporting and Data System Version 2018: what radiologists need to know. J Comput Assist Tomogr 44(2):168-177

39. Landais P, Grünfeld J-P, Droz D et al (1984) Cholangiocellular carcinoma in polycystic kidney and liver disease. Arch Intern Med 144(11):2274-2276

40. Singham J, Yoshida EM, Scudamore CH (2009) Choledochal cysts: part 2 of 3: Diagnosis. Can J Surg 52(6):506

41. Singham J, Yoshida EM, Scudamore CH (2010) Choledochal cysts: part 3 of 3: management. Can J Surg 53(1):51

42. Sharma S, Dean AG, Corn A et al (2008) Ciliated hepatic foregut cyst: an increasingly diagnosed condition. Hepatobiliary Pancreat Dis Int 7(6):581-589

43. Khoddami M, Kazemi Aghdam M, Alvandimanesh A (2013) Ciliated hepatic foregut cyst: two case reports in children and review of the literature. Case Rep Med 2013:372017

44. Bogner B, Hegedus G (2002) Ciliated hepatic foregut cyst. Pathol Oncol Res 8(4):278-279

45. Lalli AF (1967) Multicystic kidney disease. Radiology 89(5):857-860

46. Hildebrandt F, Benzing T, Katsanis N (2011) Ciliopathies. N Engl J Med 364(16):1533-1543

47. Blowey DL, Querfeld U, Geary D, Warady BA, Alon U (1996) Ultrasound findings in juvenile nephronophthisis. Pediatr Nephrol 10(1):22-24

48. Maher ER, Neumann HP, Richard S (2011) von Hippel-Lindau disease: a clinical and scientific review. Eur J Hum Genet 19(6):617-623

49. Choyke PL, Glenn GM, Walther MM, Patronas NJ, Linehan WM, Zbar B (1995) von Hippel-Lindau disease: genetic, clinical, and imaging features. Radiology 194(3):629-642

50. Choyke PL, Glenn GM, Walther MM et al (1992) The natural history of renal lesions in von Hippel-Lindau disease: a serial CT study in 28 patients. AJR Am J Roentgenol 159(6):1229-1234

51. von Ranke FM, Zanetti G, e Silva JL et al (2015) Tuberous sclerosis complex: state-of-the-art review with a focus on pulmonary involvement. Lung 193(5):619-627

52. Ewalt DH, Sheffield E, Sparagana SP, Delgado MR, Roach ES (1998) Renal lesion growth in children with tuberous sclerosis complex. J Urol 160(1): $141-145$

53. Scarsbrook AF, Thakker RV, Wass JA, Gleeson FV, Phillips RR (2006) Multiple endocrine neoplasia: spectrum of radiologic appearances and discussion of a multitechnique imaging approach. Radiographics 26(2):433-451

54. Pannett A, Thakker R (1999) Multiple endocrine neoplasia type 1. Endocr Relat Cancer 6(4):449-473

55. Feigelson J, Pecau Y, Poquet M et al (2000) Imaging changes in the pancreas in cystic fibrosis: a retrospective evaluation of 55 cases seen over a period of 9 years. J Pediatr Gastroenterol Nutr 30(2):145-151

56. Monti L, Salerno T, Lucidi V et al (2001) Pancreatic cystosis in cystic fibrosis: case report. Abdom Imaging 26(6):648-650

57. la Denise JP a, Hubert D, Gaudric M, Scatton O, Soubrane O (2011) Pancreatic mucinous cystadenoma in an adult with cystic fibrosis. Clin Res Hepatol Gastroenterol 35(11):759-761

58. Liu R, Adler DG (2014) Duplication cysts: diagnosis, management, and the role of endoscopic ultrasound. Endosc Ultrasound 3(3):152-160

59. Lee NK, Kim S, Jeon TY et al (2010) Complications of congenital and developmental abnormalities of the gastrointestinal tract in adolescents and adults: evaluation with multimodality imaging. Radiographics 30(6):14891507

60. Bhatia V, Tajika M, Rastogi A (2010) Upper gastrointestinal submucosal lesions-clinical and endosonographic evaluation and management. Trop Gastroenterol 31(1):5-29

61. Domajnko B, Salloum RM (2009) Duplication cyst of the sigmoid colon. Gastroenterol Res Pract 2009:918401

62. Alqahtani A, Nguyen LT, Flageole H, Shaw K, Laberge JM (1999) 25 years' experience with lymphangiomas in children. J Pediatr Surg 34(7):1164-1168

63. Mendez-Gallart R, Solar-Boga A, Gomez-Tellado M, Somoza-Argibay I (2009) Giant mesenteric cystic lymphangioma in an infant presenting with acute bowel obstruction. Can J Surg 52(3):E42-E43

64. O'Brien M, Winter D, Lee G, Fitzgerald E, O'Sullivan G (1999) Mesenteric cysts - a series of six cases with a review of the literature. Ir J Med Sci 168(4):233 
65. Chang TS, Ricketts R, Abramowksy CR et al (2011) Mesenteric cystic masses: a series of 21 pediatric cases and review of the literature. Fetal Pediatr Pathol 30(1):40-44

66. Kahriman G, Ozcan N, Dogan S, Bayram A (2016) Imaging findings and management of diaphragmatic mesothelial cysts in children. Pediatr Radiol 46(11):1546-1551

67. Schumpelick V, Steinau G, Schluper I, Prescher A (2000) Surgical embryology and anatomy of the diaphragm with surgical applications. Surg Clin North Am 80(1):213-239

68. Razek A, Elhanbly S, Eldeak A (2010) Transrectal ultrasound in patients with hematospermia. J Ultrasound 13(1):28-33

69. Shebel HM, Farg HM, Kolokythas O, El-Diasty T (2013) Cysts of the lower male genitourinary tract: embryologic and anatomic considerations and differential diagnosis. Radiographics 33(4):1125-1143

70. McDermott VG, Meakem T 3rd, Stolpen A, Schnall M (1995) Prostatic and periprostatic cysts: findings on MR imaging. AJR Am J Roentgenol 164(1): 123-127

71. Parada Villavicencio C, Adam SZ, Nikolaidis P, Yaghmai V, Miller FH (2016) Imaging of the urachus: anomalies, complications, and mimics. Radiographics 36(7):2049-2063

72. Pereira B, Sousa L, Azinhais P et al (2009) Zinner's syndrome: an up-to-date review of the literature based on a clinical case. Andrologia 41(5):322-330

\section{Publisher's Note}

Springer Nature remains neutral with regard to jurisdictional claims in published maps and institutional affiliations.

\section{Submit your manuscript to a SpringerOpen ${ }^{\odot}$ journal and benefit from:}

- Convenient online submission

- Rigorous peer review

- Open access: articles freely available online

- High visibility within the field

- Retaining the copyright to your article

Submit your next manuscript at $\boldsymbol{\nabla}$ springeropen.com 